\title{
Radiation-induced modifications in natural fibres and their biocomposites: Opportunities for controlled physico-chemical modification pathways?
}

\author{
Nicolas Le Moigne ${ }^{\mathrm{a}, *}$, Rodolphe Sonnier ${ }^{\mathrm{a}, *}$, Roland El Hage ${ }^{\mathrm{a}, 1}$, Sophie Rouif $\mathrm{f}^{\mathrm{b}}$ \\ a Centre des Matériaux des Mines d'Alès (C2MA), Ecole des mines d'Alès, 6 avenue de Clavières, 30319 Alès Cedex, France ${ }^{2}$ \\ b Ionisos SAS, Parc Dombes Côtière Activités, 01120 Dagneux, France
}

\section{A B S T R A C T}

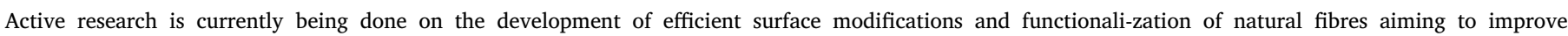

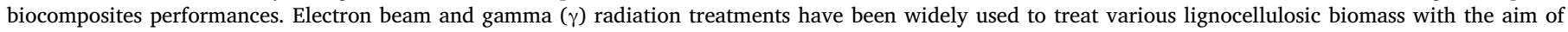

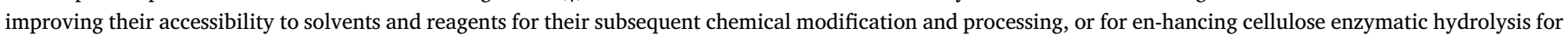

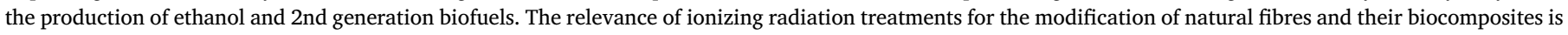

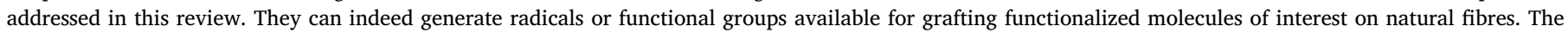

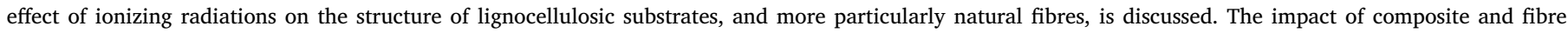

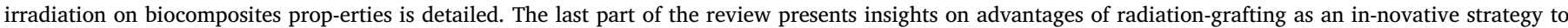

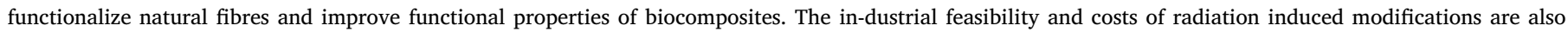

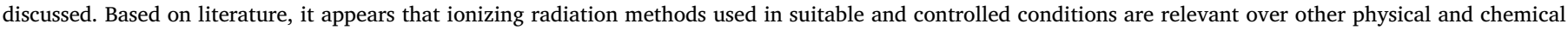
methods developed for the surface modification and functionalization of bio-reinforcements in com-posite applications.

Keywords:

Natural fibres

Biocomposites

e-Beam and $\gamma$-irradiation

Functionalization

\section{Introduction}

Nowadays, natural fibres are considered as a promising alternative to synthetic fibres, such as glass, in composite applications (Deyholos and Potter, 2014; Faruk et al., 2012). Biocomposites reinforced with lignocellulosic or protein fibres have some advantages over glass fibre based composites, thanks to their biobased and renewable origin and biodegradability, low cost, low density, low abrasiveness and good damping performances. Natural fibres also exhibit high specific mechanical properties (i.e. mechanical properties to fibre density ratio), even if their ultimate performances still remain lower than those of glass fibres. Besides, the low thermal stability of natural fibres limits their use in composite applications to polymer matrices having low processing temperatures.

In particular, mechanical properties of biocomposites suffer from the low mechanical interlocks and physico-chemical interactions at the fibre/matrix interface. The quality of the interfacial adhesion is primarily related to the differences in surface energy and polarity between matrix and fibres, the fibre surface topography, as well as the availability of reactive functional groups at the fibre surface and the possible presence of weakly bonded components on the fibres. Other parameters can be considered as the presence of moisture into natural fibres or their intrinsic porosity which may act as weak points within their microstructure or at the fibre/matrix interface. In this respect, glass fibrebased composites, for which fibre sizing intended to improve fibre/ matrix adhesion was widely developed over the last decades, generally exhibit much higher mechanical performances.

Strategies to improve the adhesion between natural fibres and matrix are focused in particular to the surface modification of natural fibres. Because the nature of lignocellulosic substrates is totally different from that of glass fibres, the sizing formulations used for the latter cannot be directly applied for the former. Thereby, active research is currently being done on the development of efficient surface modifications and functionalization of natural fibres aiming to improve the performances of biocomposites. Hydrophobic treatments are also considered to control the water uptake of these fibres in composite and

\footnotetext{
* Corresponding authors.

E-mail addresses: nicolas.le-moigne@mines-ales.fr (N. Le Moigne), rodolphe.sonnier@mines-ales.fr (R. Sonnier).

${ }^{1}$ Current address: Laboratoire de Chimie-physique des matériaux (LCPM), Université Libanaise, Faculté des Sciences II, Fanar, Liban.

${ }^{2}$ C2MAis member of the European Polysaccharide Network of Excellence (EPNOE), http://www.epnoe.eu.
} 
textile applications. Among many other chemical and physical treatment methods (Belgacem and Gandini, 2005; Faruk et al., 2012; Kalia et al., 2009), electron beam (e-beam) and gamma $(\gamma)$ radiation treatments have been widely used to treat various lignocellulosic biomass with the aim of improving their accessibility to solvents and reagents for their subsequent chemical modification and processing, or for enhancing cellulose enzymatic hydrolysis for the production of ethanol and 2nd generation biofuel (Arthur, 1971; Driscoll et al., 2009; Fischer et al., 1985; Klemm et al., 1998; Loow et al., 2016). Irradiation can also be used to modify natural fibres, and generate radicals or functional groups available for grafting functionalized molecules of interest. Nevertheless, it is well known since several decades that ionizing radiations can degrade cellulosic substrates, at relatively low ionizing doses. Therefore, the relevance of these ionizing radiation methods for the modification of natural fibres is questionable (Belgacem and Gandini, 2005).

In this review, we recall briefly the main molecular and microstructural features of natural fibres. The influence of ionizing radiations on lignocellulosic substrates, and more particularly on natural fibres at the different scales of their structure, is discussed according to the main characteristics and influencing parameters (dose, atmosphere, moisture...) of both e-beam and $\gamma$-radiations. Then, the impact of preirradiation of fibres or matrix and of post-irradiation of biocomposites is also detailed. Indeed, it is important to identify the effective role of fibre irradiation when radiation-induced changes or radiation-grafting are considered to improve the interfacial interactions between natural fibres and matrices. Insights on advantages of radiation-grafting as an innovative strategy to functionalize natural fibres and improve fibre/ matrix interactions in biocomposites are exposed. The last part of the review propose a discussion on the industrial feasibility and costs of radiation induced modifications.

\section{Molecular and cell wall structure of natural fibres}

Natural fibres usually refer to lignocellulosic biomass such as wood fibres and other plant cells from fruit, grass, leaf, seed, and stem. Their chemical composition varies within the different parts of the plant, from one plant to another, according to soil and climate conditions, and maturity of the cells. When considering the dry matter, the predominant chemical components are carbohydrates (sugar-based polymers: holocellulose " cellulose and hemicelluloses » and pectins) in combination with a complex polymer of aromatic alcohols named lignin, and in lower amounts, extractives (e.g. fatty acids, fatty alcohols, free sterols, ferulic acid esters, waxes, sterol, and other aromatic compounds), starch, proteins and inorganic components (e.g. silicon, calcium, potassium, zinc, iron, aluminum, boron, etc.) (Bismarck et al., 2002; Brosse et al., 2012; Gutierrez et al., 2008; Misra et al., 1993; Yan et al., 2014). Cellulose is the most abundant biopolymer on the planet, representing more than half of the Earth's biomass. It is indeed estimated that nature produces between $10^{10}$ and $10^{11}$ tons of cellulose annually, which constitutes at least $50 \%$ of the plant mass (Hon, 1994). Cellulose is a linear homopolymer of chemical formula $\mathrm{C}_{6} \mathrm{H}_{10} \mathrm{O}_{5}$. The macromolecular chains are composed of anhydroglucose units (AGU) linked together by $\beta-(1,4)$-glycosidic bonds, and are associated through intra and inter-molecular hydrogen bonds and organized in crystalline elementary fibrils of about $3.5 \mathrm{~nm}$ in diameter and microfibrils of 4-35 nm in diameter according to cellulose sources (Klemm et al., 2005). Degree of polymerization (DP) of native cellulose from various origins varies from 1000 to 30,000 with a large polydispersity, and from 200 to 3000 after extraction (Heinze et al., 2012; Klemm et al., 1998; Krässig, 1993). Cellulose substrates may contain as much as $70 \%$ of highly ordered crystalline regions (Atchison, 1983; O'Sullivan, 1997), whose main lattice forms are either type I for native cellulose or type II for regenerated cellulose. Thanks to its well-organized structure, cellulose provides strength, stiffness and structural stability to natural fibres. The hemicellulose fraction of natural fibres consists in branched heteropolysaccharides, mainly xylans, mannans and xyloglucans, containing $5\left(\mathrm{C}_{5} \mathrm{H}_{10} \mathrm{O}_{5}\right)$ and $6\left(\mathrm{C}_{6} \mathrm{H}_{12} \mathrm{O}_{6}\right)$ carbon sugars: D-xylopyranose, Dglucopyranose, D-galactopyranose, L-arabinofuranose, D-mannopyranose, and D-glucopyranosyluronic acid with minor amounts of other sugars. Hemicelluloses, in their native state, are low molecular weight branched polymers which are non-crystallizable but still contribute to the structural organization of the plant cells as a matrix component (Pettersen, 1984). Pectins are complex high-molecular-weight acidic polysaccharides whose chain backbone is rich in galacturonic acid with different degree of methyl esterification. The most common pectic polysaccharides present in natural fibres are linear homogalacturonans and branched rhamnogalacturonans (RG type I, RG type II). They act as adhesives in the middle lamellae between plant cells and contribute to the mechanical strength of the cell walls (Jarvis, 1984; Morvan et al., 2003). Non-wood fibres (e.g. bast fibres) have significant amount of pectins in their structure. Lignin is a three-dimensional phenylpropanoid heterogeneous, amorphous and highly cross-linked macromolecule that represents the second most abundant natural polymeric material on earth. Despite extensive investigations, the complex and irregular structure of lignin is not completely understood (Argyropoulos and Menachem, 1998; El Hage et al., 2010a,b; Fengel and Wegener, 1989). Lignin structure varies within different plant species and is usually composed of three basic building blocks of guaiacyl, syringyl, and p-hydroxyphenyl moieties, although other aromatic type units also exist in many different types of plants (Sjöström, 1981). Lignin is considered as a cell wall adhesive that also acts as an encrusting component between cellulose microfibrils, like the matrix constituents mainly composed of hemicelluloses and pectins (Morvan et al., 2003). Chemical compositions of some selected natural fibres are given in Table 1.

In general, the cell wall morphology of natural fibres (Fig. 1) is made of an outer layer, the primary (P) wall (0.1-0.5 $\mu \mathrm{m}$ thick), and concentric inner layers constituting the secondary (S1) and (S2) walls $(0.1-0.3 \mu \mathrm{m}$ and $1-10 \mu \mathrm{m}$ thick, respectively), where the different chemical components detailed above are distributed and organized, thereby forming a complex, tri-dimensional bio-assembly (Klemm et al., 1998; Klemm et al., 2005; Krässig, 1993). In these different layers and walls, cellulose microfibrils are oriented along the fibre axis and holded together due to cooperative function of hemicelluloses, lignin and pectins that act as matrix and adhesive components (Sjöström, 1981). These fibrillar cells, also called elementary fibres, are gathered in fibre bundles into wood and grass, and within the stem, fruit or leaf of annual plants, or can be eventually already individualized as is in the case of cotton fibres. A combined method using visible photomicrograph, associated with a 3-D mid-infrared transmission, allowed to localize the distribution of the different cellulosic and non-cellulosic components across flax stem sections (Morvan et al., 2003), and showed that stem surface (epidermal region) is composed mainly of pectins and waxes. Underneath the epidermis, the internal zone rich in bast fibres, where cellulose is predominant, showed substantial amounts of pectins and acetylated non-cellulosic polysaccharides accumulated in the primary wall and cell junction that act as adhesives in the cohesion of flax fibre bundles. Aromatic components (e.g. lignins) and non-cellulosic polysaccharides appeared to be more concentrated in the core tissues of flax stems. These observations thus show that natural fibres can undergo wide variations in biochemical composition according to their localization within higher plants.

Bismarck et al. (2002) proved that surface characteristics of natural fibres vary according to fibre extraction and separation processes. As observed by scanning electron microscopy (SEM), BET-adsorption and $\xi$-potential measurements, extraction processes affect the surface morphology and the specific surface area of fibres as well as their surface physical chemistry. In particular, the hydrophilic character of natural fibres is related to the amount of waxes on their surface. Lower waxes content leads to higher hydrophilicity and to higher water sorption (Kuehn et al., 1986). Furthermore, the content and the nature of surface 
Table 1

Biochemical composition of some selected natural fibres.

\begin{tabular}{|c|c|c|c|c|c|c|c|}
\hline $\begin{array}{l}\text { Natural fibre } \\
\text { type }\end{array}$ & $\% w t$ cellulose & $\begin{array}{l}\text { \%wt } \\
\text { hemicellulose }\end{array}$ & \%wt lignin & \%wt pectins & $\begin{array}{l}\text { \%wt fat/ } \\
\text { wax }\end{array}$ & \%wt ash & references \\
\hline Hardwood & $38-51$ & $17-31$ & $21-31$ & - & - & - & Sjöstrom (1993) \\
\hline Softwood & $33-41$ & $20-29$ & $27-32$ & - & - & - & Sjöstrom (1993) \\
\hline Flax & $60-81$ & $14-21$ & $2-5$ & $0.9-3.8$ & $1.3-1.7$ & 1.5 & Müssig et al. (2010) \\
\hline Hemp & $57-92$ & $6-22$ & $2.8-13$ & $0.8-2.5$ & $0.7-0.8$ & $0.7-3$ & Müssig et al. (2010) \\
\hline Jute & $51-84$ & $12-24$ & $5-14$ & $0.2-4.5$ & $0.4-0.8$ & $0.5-2$ & Müssig et al. (2010) \\
\hline Ramie & $68-87$ & $3-17$ & $0.2-1$ & $1.7-2.1$ & 0.3 & $0.3-1.2$ & Müssig et al. (2010); Thakur et al. (1999) \\
\hline Miscanthus & $37-45$ & $18-36$ & $20-26$ & - & $1-2$ & $2-6$ & $\begin{array}{l}\text { Brosse et al. (2010); El Hage et al. } \\
\text { (2010a,b); Montane et al. (1998); Sørensen } \\
\text { et al. (2008) }\end{array}$ \\
\hline Bamboo & $26-43$ & $15-30$ & $21-31$ & - & - & $0.9-2.8$ & Müssig et al. (2010); Wahab et al. (2013) \\
\hline Piassava & 29 & 26 & $45-48$ & - & - & - & $\begin{array}{l}\text { Ferreira et al. (2014); John and } \\
\text { Anandjiwala, (2008) }\end{array}$ \\
\hline Kenaf & $36-72$ & $20-23$ & $8-19$ & $2-5$ & - & - & $\begin{array}{l}\text { Müssig et al. (2010); Lilholt and Lawther } \\
\text { (2000) }\end{array}$ \\
\hline Sisal & $43-88$ & $10-15$ & $4-14$ & $0.5-10$ & $0.2-2$ & $0.1-0.5$ & Müssig et al. (2010); Varghese et al. (1994) \\
\hline Henequen & $60-78$ & $4-28$ & $8-13$ & $3-4$ & 0.5 & - & Han et al. (2006a); Müssig et al. (2010) \\
\hline Banana & $50-68$ & $6-30$ & $5-18$ & $3-5$ & $10-11$ & 1.2 & Joseph et al. (2002); Müssig et al. (2010) \\
\hline Cotton & $82-96$ & $2-6$ & $0-1.6$ & $0-7$ & 0.6 & $0.8-2$ & $\begin{array}{l}\text { Müssig et al. (2010); Lilholt and Lawther } \\
\text { (2000) }\end{array}$ \\
\hline Silk & $\begin{array}{l}\text { Two proteins: light chains (hundreds } \\
\text { amino-acids), heavy chains (thousands } \\
\text { amino-acids) }\end{array}$ & & & & & & Müssig et al. (2010); Shubhra et al. (2010) \\
\hline
\end{tabular}

components depend on the natural fibre considered. Marques et al. (2010) have analysed by gas chromatography - mass spectrometry the lipophilic extractives of four natural fibre types (flax, hemp, sisal, abaca). Extraction was carried out by acetone using Soxhlet during $8 \mathrm{~h}$. Several lipophilic components were identified: fatty alcohols, fatty acids, alkanes, aldehydes, steroids, free and conjugated sterols, triterpenoids and ester waxes. Molecular weights of these components can be relatively high: for example, ester waxes containing 50 carbon atoms were identified for flax fibre. Great differences were observed between the different fibre types. Hence, the concentration of fatty acids content was $552 \mathrm{mg}$ per $100 \mathrm{~g}$ for flax versus $9 \mathrm{mg}$ per $100 \mathrm{~g}$ for sisal or abaca. Extractives total content is also significantly higher for flax.

Considering the complex hierarchical and layered structure of natural fibres, irradiation should affect the surface as well as the bulk of the fibres at the different scales of their structure, from the microstructural down to the macromolecular level. As will be discussed, ebeam and gamma irradiation are thus responsible for significant modifications in the surface physical chemistry, the thermal and the mechanical behaviour of natural fibres.
3. Effect of irradiation on the molecular structure, microstructure and physical properties of natural fibres

\subsection{Intra and inter-molecular changes in cellulose and non-cellulosic components}

The effect of irradiation has been studied on various lignocellulosic substrates with the aim of improving accessibility to solvents, chemical reagents or enzymes, and hence increasing cellulose dissolution capacity for its subsequent processing or the extent of cellulose enzymatic hydrolysis for the production of ethanol and 2nd generation biofuels (Arthur, 1971; Driscoll et al., 2009; Fischer et al., 1985; Klemm et al., 1998; Loow et al., 2016). In all the studies, a strong decrease of the molecular weight of cellulose has been reported depending on the radiation dose and energy. Takács et al. (1999) observed a 70\% drop of the DP for cotton fibres $\gamma$-irradiated at $15 \mathrm{kGy}$ with a further gradual decrease for higher radiation doses. Similar results were obtained by Bouchard et al. (Bouchard et al., 2006). The authors measured a decrease of $70 \%$ of the DP for cotton fibres irradiated by electron-beam at $20 \mathrm{kGy}$ followed by a slow decrease up to $240 \mathrm{kGy}$. The chain scission number was also found to be proportional to the radiation dose. In the

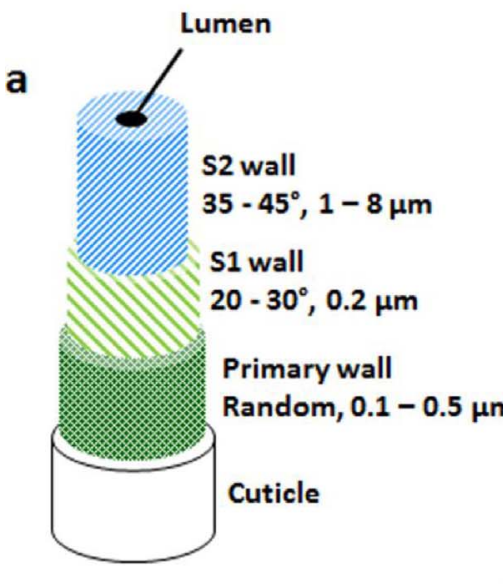

b

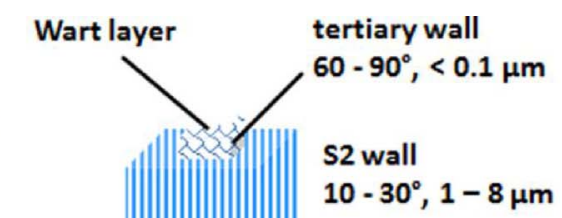

S1 wall

$50-70^{\circ}, 0.3 \mu \mathrm{m}$

Primary wall

Random, $0.1-0.5 \mu \mathrm{m}$

Fig. 1. Cell wall structure of a cotton fibre (a) and wood fibre (b), with: cuticle (rich in pectins and waxes), lumen, middle lamella (mainly lignin), primary wall, S1-secondary wall, S2-secondary wall (main body), tertiary wall, wart layer. For each wall, the thickness and the microfibrillar orientation are drawn according to (Klemm et al., 1998; Krässig, 1993; Warwicker et al., 1996). 
same study, the effect of electron-beam irradiation on kraft softwood and hardwood pulps, containing hemicelluloses, was investigated. No significant deviation in the cellulose chain scission number was found when comparing the different cellulose substrates. Based on these results, the authors assumed that radiation-induced cellulose chain scission is independent of the fibre origin and composition or the pulping process. Comparing the chain scission number of cellulose per unit of irradiation dosage obtained from weight-average and z-average DPs, the authors did not find significant differences, indicating that radiation-induced cellulose chain scission is a totally random process. Furthermore, Bouchard et al. (2006) observed that the decrease in DP at a constant dosage was higher for lower electron beam energy (at the level of energy tested, 4.5 and $10 \mathrm{MeV}$ ). They postulated that different beam energies may cascade into different mixtures of X-rays and secondary electrons as it hits cellulosic substrates, which should have an influence on the number of radicals formed and the resulting number of cellulose chain scissions. Similar results regarding the drop of cellulose DP were also found by Iller et al. (2002) and Stupińska et al. (2007) when studying the effect of electron-beam irradiation on several textile and kraft wood pulps, and by Driscoll et al. (2009) for micro-crystalline cellulose (MCC). Besides, it must be noticed that Iller et al. (2002) and Han et al. (Han et al., 2007) observed a significant decrease of the amount of $\alpha$-cellulose (high-molecular-weight cellulose) with increasing radiation dose for wood pulps and kenaf fibres, respectively. Summarizing, a drastic decrease of the DP was observed even at low radiation dose whatever the cellulose substrate and the type of irradiation used, i.e. $\gamma$ or electron-beam. As shown on Fig. 2, based on all the studies cited above, a radiation dose of $25 \mathrm{kGy}$ is sufficient to decrease the relative cellulose DP (ratio of the DP after radiation treatment to the initial $\mathrm{DP}_{0}$ of cellulosic substrates) by three for all the studied cellulose substrates, which corresponds to an average chain scission number of 2.3 per cellulose chain. It should be pointed that studies on cellulose DP measurements after irradiation for natural fibres other than wood pulps and cotton fibres are scarce in literature. This is mostly due to the complex structures and larger amount of non-cellulosic components in natural fibres that make difficult the isolation of cellulose and the measurement of its DP.

The main mechanism involved in radiation-induced cellulose degradation is the formation of free radicals at the atoms C- 1 and C- 4 of the AGU that initiate glycosidic bonds cleavage and the degradation of cellulose by random chain scission (Arthur, 1971; Klemm et al., 1998). Cross-linking could also be observed especially at low radiation dose, i.e. lower than $10 \mathrm{kGy}$ (Pruzinec et al., 1981). Based on electron paramagnetic resonance spectroscopy (ESR) experiments on irradiated textile and kraft pulps, Iller et al. (2002) confirmed the correlation between the irradiation dose, the concentration of free radicals formed in the cellulose substrates and the resulting decrease in DP. These experiments also showed that the free radicals concentration in wood

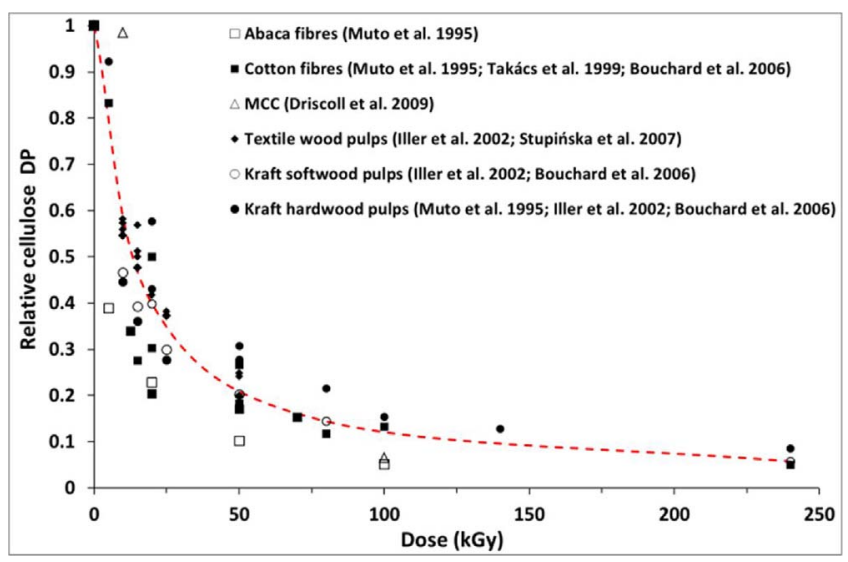

Fig. 2. Relative cellulose DP versus radiation dose for various cellulose substrates.

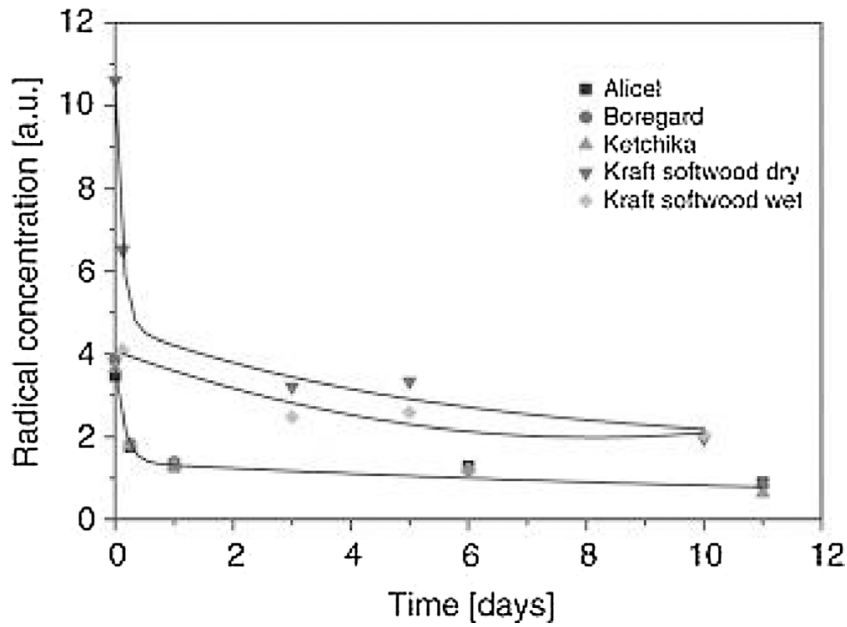

Fig. 3. Decay of free radicals in different types of cellulose pulps irradiated with $10 \mathrm{MeV}$ electron beam. Reproduced from Iller et al. (2002), Fig. 1 with permission from Elsevier.

pulps increases linearly until $25 \mathrm{kGy}$ to rise then more slowly at higher doses due to radiolytic saturation effects. These free radicals can be either formed in the less ordered and more accessible regions or trapped in crystalline regions, thus influencing their lifetime and reactivity. After irradiation, the number of free radicals decreases rapidly during the first hours after irradiation, then to remain constant at approximately $20-25 \%$ of the initial concentration, long-lived free radicals being mostly localized in crystalline regions (Fig. 3). Even after one month' storage, radicals are still detected in irradiated cellulose from cotton fabrics (Takács et al., 2005). The formation and the lifetime of free radicals decrease with increasing moisture content in the cellulose substrates due to their interaction with water, especially in the less ordered regions more accessible to water molecules (Arthur, 1971; Fischer and Goldberg, 1987; Iller et al., 2002). Moreover, the presence of oxygen during irradiation enhances cellulose degradation, probably due to the reaction of oxygen with radicals formed at the atom C-5 that induces the AGU ring cleavage (Arthur, 1971). While not changing the degradation processes, temperature also have a significant effect on the decomposition yield of cellulose, especially above $100{ }^{\circ} \mathrm{C}$, because it favours the transfer of radicals formed upon irradiation to neighbouring cellulose chains (Ponomarev and Ershov, 2014).

As cellulose degradation occurs with increasing irradiation doses, Arthur (1971) and Takács et al. (1999) suggested that the decrease in DP should also result in an enhanced molecular mobility of cellulose chains. This higher molecular mobility is favourable to conformational changes and responsible for increased inter-molecular hydrogen bonding between the cellulose chains, as well as inter-chain crosslinks through neighbouring radicals. Such phenomenon was supported by Fourier transform infrared spectroscopic (FTIR) measurements on cotton fibres that showed a shift and a strengthening of the absorbance of $\mathrm{OH}$ groups to higher wavenumber $\left(3200-3300 \mathrm{~cm}^{-1}\right)$, indicating an increase of intermolecular hydrogen bonds at the expense of intramolecular hydrogen bonds (Takács et al., 1999; Tóth, Borsa, \& Takács, 2003). A reduction in the height of the peak assigned to intramolecular hydrogen bonds $\left(3044 \mathrm{~cm}^{-1}\right)$ was also reported for irradiated jute fibres (Khan et al., 2006). Based on these observations, Takács and co-workers (Borsa et al., 2003; Foldváry et al., 2003; Takács et al., 1999, 2000; Tóth et al., 2003) investigated the role of cellulose accessibility on radiation-induced changes through the influence of dissolution, swelling and chemical modification of cotton fibres on postirradiated or pre-irradiated samples. Cotton fibres were dissolved in Cuen (cupriethylenediamine) then post-irradiated at increasing radiation doses. It was shown that the degradation is greatly enhanced when cellulose is irradiated in the solution state as compared to the solid state (Takács et al., 1999). Besides, it was observed that carboxymethylation 
of cotton fibres led to a higher number of chain cleavages during irradiation (Borsa et al., 2003). Cotton fibres were also swelled in aqueous solutions of sodium hydroxide $(\mathrm{NaOH})$ and tetramethylammonium hydroxide (TMAH), respectively. After neutralization and drying, the pre-swelled fibres were irradiated at 3 and $10 \mathrm{kGy}$. In these conditions, a limited decrease of the DP was measured for pre-swelled fibres as compared to unswollen ones after irradiation at $10 \mathrm{kGy}$. This was explained by the increased molecular mobility in the amorphous regions brought by the swelling treatments, which favour cross-linking upon irradiation and restrained the decrease in DP. This phenomenon was more pronounced for the TMAH treatment due to its better swelling ability (Tóth et al., 2003). Conversely, the pre-irradiation of cotton fibres and their subsequent treatment in $\mathrm{NaOH}$ or TMAH solutions (Foldváry et al., 2003; Takács et al., 2000) were responsible for a significant weight loss of the samples due to partial dissolution of the degraded cellulose chains. These results thus show that the use of swelling treatments or chemical modifications to enhance cellulose accessibility and chain mobility can promote the interlinkage between the cellulose chains during irradiation, through inter-molecular hydrogen bonding and cross-linking. In specific conditions, chain scission and cross-linking mechanisms can coexist and act antagonistically on the measured variations in DP. It must be noticed that this particular phenomenon should occur at relatively low radiation dose ( $<10 \mathrm{kGy})$ (Arthur, 1971; Pruzinec et al., 1981) and for moderately swollen fibres. Fibres placed in a highly swollen or dissolved state and subjected to radiation, degrade drastically. Moreover, the radiation yield of cellulose depolymerisation is much higher than the yield of intermolecular bonding formation (Arthur, 1971).

Aside the cleavage between the AGU units and the modification of the intra and inter-hydrogen bonds network, irradiation also induces cleavages within the pyranose ring with generation of radicals at C-2, C3 and C-4 positions (Dubey et al., 2004). This results in the release of gaseous products such as water, hydrogen, carbon monoxide and carbon dioxide. The subsequent oxidative degradation of cellulose leads to the formation of carbonyl groups $(\mathrm{C}=\mathrm{O})$ and carboxyl groups $(\mathrm{COOH})$ in cellulose substrates, especially in open air and high temperature conditions (Arthur, 1971; Ponomarev and Ershov, 2014). Based on FTIR experiments, it has been shown that the relative absorbance of the band related to carbonyl groups $\left(\sim 1740 \mathrm{~cm}^{-1}\right)$ increases linearly with the radiation dose for gamma irradiated cotton fibres (Takács et al., 2000). Based on the oximation of carbonyl groups and the determination of the nitrogen content by the Kjeldahl method, Bouchard et al. (2006) quantified the carbonyl content in kraft wood pulps and cotton fibres as a function of e-beam irradiation dose (Fig. 4a). The authors also found a linear correlation with a significant increase of the relative carbonyl concentration of about 5 times per 100 $\mathrm{kGy}$, independently of the cellulose substrate and the level of energy tested. Bouchard et al. (2006) also investigated the variation in the relative carboxyl group concentration in kraft wood pulps and cotton fibres by the methylene blue sorption procedure (Fig. 4b). The authors did not find significant increase of carboxylic group for kraft wood pulps, whereas in cotton fibres, the relative carboxyl group concentration increased almost linearly by a factor 1.4 per $100 \mathrm{kGy}$ between $50 \mathrm{kGy}$ and $240 \mathrm{kGy}$. This was in accordance with the study of Muto et al. (1995), in which only cotton showed the formation of carboxyl groups, in contrast with kraft hardwood pulp and abaca. Bouchard et al. (2006) postulated that the presence of hemicelluloses in kraft wood pulps may inhibit the formation of carboxyl groups during irradiation but no explanation was given on the chemical mechanisms involved.

Non-cellulosic components, i.e. hemicelluloses, pectins and lignin, located within the cell wall structure and in between elementary fibres, and waxes present at the fibre surface, are also significantly affected by irradiation as well as their respective interactions within the fibre structure. Nevertheless, it is worth mentioning that there is much less literature available on this topic. Studying the effect of irradiation on giant reed and Chinese silvergrass at high doses (i.e. 400-1200 kGy), Li et al. (2016) found that hemicelluloses degrade much faster than cellulose while the degradation rate of lignin was the smallest among the three components. Shin et al. investigated the interest of e-beam irradiation to isolate cellulosic fibres from kenaf (Shin et al., 2012). They found that the treatment of raw kenaf bast fibre at high radiation doses ( $300 \mathrm{kGy}$ ) favours the subsequent extraction of lignin and hemicellulose by water cooking and bleaching processes, attesting for the partial degradation of lignin and hemicellulose and modifications of their interactions with cellulose. As concern hemicelluloses, degradation mechanisms are similar to cellulose. They are expected to occur through a fast depolymerisation by the cleavage of glycosidic bonds and a partial splitting off of xylan branches. Li et al. (2016) also showed that degradation under irradiation of hemicelluloses from giant reed and Chinese silvergrass results in the released of water-soluble sugars such as arabinose, glucuronic acid and galacturonic acids depending on plant species.

Fischer and Goldberg (1987) reviewed the potential effect of irradiation on beech wood components. As discussed by the authors, radiation-induced changes in lignin are initiated preferentially by phenoxy radicals and proceed through oxidative mechanisms that cause condensation but also depolymerisation of lignin. Depending of lignocellulosic substrates, lignin degradation leads to the formation of aromatic compounds such as aromatic aldehydes and acids, phenolics and fatty acids (Hendriks and Zeeman, 2009). As an example, Li et al. (2016) showed the great influence of gamma irradiation on the formation of vanillic aldehyde for giant reed and Chinese silvergrass while no significant change in the amount of p-coumaric acid was measured. Moreover, Fischer and Goldberg (1987) reported the potential formation of complexes between lignin and carbohydrates during irradiation. While studying the effect of electron beam irradiation on starch-lignin films, Lepifre et al. (2004) also assumed the formation of covalent bonds between lignin and starch as well as the self-cross-linking of lignin during irradiation, resulting in an increased hydrophobicity of the films. Based on DP measurements after irradiation of isolated and non-isolated holocellulose from redwood, Smith and Mixer (1959) suggested that aromatic compounds in lignin and other wood extractives can play a protective role on the radiolysis of cellulose. Indeed,
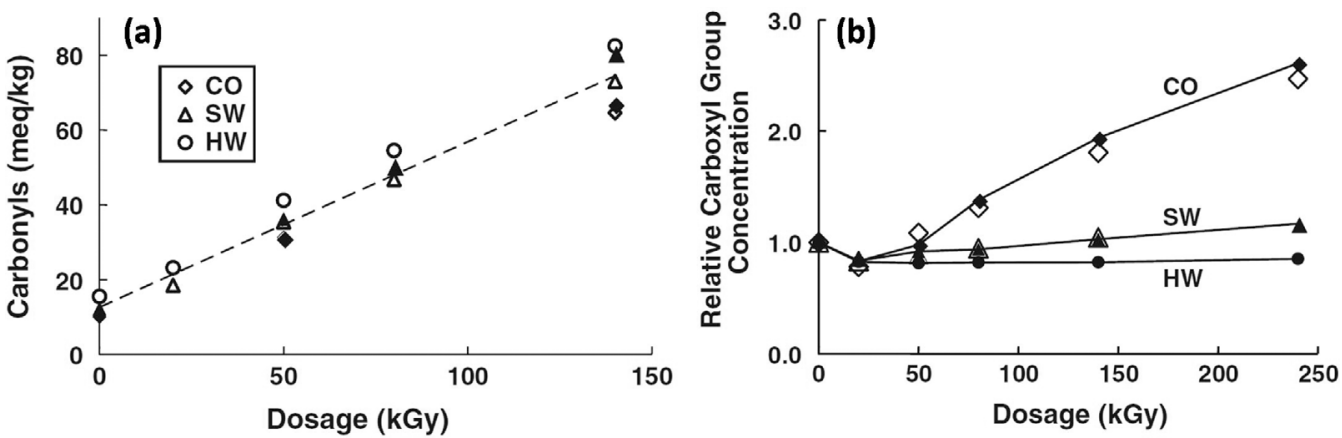

Fig. 4. (a) Carbonyl group concentration $(\mathrm{meq} / \mathrm{kg}$ ) and (b) relative carboxylic acid group concentration as a function of electron beam irradiation dosage for $\mathrm{CO}$ (cotton chromatographic filter), HW (bleached hardwood kraft pulp) and SW (bleached softwood kraft pulp). Reproduced from Bouchard et al. (2006), Figs. 5 and 7 with permission from Springer. 
the presence of lignin and extractives reduced significantly the average number of chain scissions from 2.4 to 1.5 at $65 \mathrm{kGy}$ and from 4.4 to 2.9 at $185 \mathrm{kGy}$.

Modifications of pectins during irradiation are much studied in food science because of their key role on tissue softening of fruits and vegetables. This softening effect appears to be strongly related to the degradation of pectins which are mostly present within the primary wall and the middle lamella of fruit cell walls (d'Amour et al., 1993; Kovács and Keresztes, 2002). In particular, d'Amour et al. (1993) showed that the irradiation of strawberries at $4 \mathrm{kGy}$ resulted in a significant hydrolysis of the unbranched polygalacturonic acid fractions constituting the backbone chains of pectins, while branched pectins with their neutral sugar side-chains were less affected by irradiation. According to the authors, branched pectic substances, preferentially present in the primary wall, may be less vulnerable to depolymerisation with free radicals due to their embedment in the cellulose and hemicellulose network. Extensive degradation of pectins during irradiation was also reported in the middle lamella of apples (Kovács and Keresztes, 2002). One can expect that similar degradation phenomena would occur for pectins from plant cell walls, thus affecting the structure of the primary wall in natural fibres, as well as the middle lamella between the elementary fibres, rich in pectic substances.

Surface analysis by X-ray photoelectron spectroscopy (XPS) of irradiated henequen fibres also revealed that waxes and impurities present at the fibre surface are easily degraded and removed by ionizing radiation even at low radiation doses (Han et al., 2006a). Considering the presence of aliphatic chains with unsaturated carbon bonds in these substances, these molecules might also react with cellulose, lignin or other carbohydrates to form crosslinks under irradiation. To our knowledge, this phenomenon was not reported yet in literature.

\subsection{Microstructural and surface changes in natural fibres}

The degradation processes and molecular changes described in the previous section are responsible for microstructural and chemical modifications in the bulk of natural fibres, i.e. cellulose crystallinity, porosity and cell wall microstructure, and at their surface, i.e. damages and roughness, specific surface area and surface functional groups.

Several research works investigated the effect of irradiation on cellulose crystallinity for various substrates. Khan et al. (2006) studied the effect of gamma irradiation on jute fibres and found a decreased intensity of the crystalline peaks from the 110 lattice plane $\left(2 \theta=10-18^{\circ}\right)$ and the 200 lattice plane $\left(2 \theta=18-30^{\circ}\right)$ and a significant decrease of the crystallinity index from $42 \%$ to $31 \%$ at $100 \mathrm{kGy}$. Studying the effect of e-beam irradiation on henequen fibres, Choi et al. (2009) also found a decreased intensity of the crystalline peak at $2 \theta=22^{\circ}$ at high radiation dose up to $500 \mathrm{kGy}$. It was also pointed out by Driscoll et al. (2009) that the crystallinity of MCC can be strongly affected by high irradiation doses. The initial crystallinity index of MCC at $87 \%$ was decreased to $65 \%$ and $45 \%$ after irradiation at $100 \mathrm{kGy}$ and $1000 \mathrm{kGy}$, respectively. On the other hand, several studies also reported no significant effect of irradiation on the crystalline structure of cellulose with no shift of the crystalline peaks, no cellulose I/cellulose II transition and a conservation of crystallinity for cotton, henequen and kenaf fibres (Arthur, 1971; Foldváry et al., 2003; Han et al., 2008; Klemm et al., 1998; Takács et al., 2000), unless reaching high radiation doses of several hundred kGy. All these results demonstrate a substantial preservation of the crystalline structure despite the drastic decrease of the DP during irradiation. The increased molecular mobility and inter-molecular interactions of cellulose chains favouring the re-organization of amorphous regions, as well as the removal of non-crystalline components present in natural fibres may counterbalance the degradation effect in crystalline regions during irradiation (Arthur, 1971; Choi et al., 2009; Klemm et al., 1998; Li et al., 2016).

Significant morphological changes and damages have also been reported after irradiation of natural fibres. Evidences of cell walls and middle lamellae degradation in wood and henequen fibres were revealed by SEM observations (Choi et al., 2009; Fischer et al., 1985; Han et al., 2006b; Han and Choi, 2010). In particular, a removal of the outer primary (P) wall and the inner secondary (S3) wall of henequen fibres was observed at relatively low radiation doses (30 kGy). Besides, small molecules such as pectins, low DP hemicelluloses, waxes and impurities are easily degraded and removed from the fibre surface even at low radiation doses $(10 \mathrm{kGy})$. This leads to modifications in the porous structure, the total pore volume and especially the volume of small pores being significantly increased. Fischer et al. (1985) measured by mercury porosimetry an increase of $6 \%$ of the total pore volume for wood fibres accompanied by an increase of $11 \%$ of the volume occupied by small pores comprised between 15 and $760 \mathrm{~nm}$. Similar results were found by Han and Choi (2010) and Choi et al. (2009) with the formation of many small pores of $40-100 \mathrm{~nm}$ measured by mercury porosimetry and $\mathrm{N}_{2}$ adsorption in henequen fibres irradiated at $30 \mathrm{kGy}$. In these studies, variations in the total micropore $(<2 \mathrm{~nm})$ and macropore $(>50 \mathrm{~nm}$ ) volume were observed according to irradiation doses but no monotonic trend could be drawn. These modifications in the porous structure related to the removal of surface components from the fibres, i.e. waxes, impurities, pectins and $\mathrm{P}$ wall, at low irradiation dose were accompanied by a significant increase of the surface area and roughness. A maximum surface area of $18.9 \mathrm{~m}^{2} / \mathrm{g}$ measured by mercury porosimetry was reached at $30 \mathrm{kGy}$ (Choi et al., 2009). This was correlated with an increase in root mean square (rms) roughness up to 268 rms at $30 \mathrm{kGy}$ as measured by atomic force microscopy (AFM) due to the presence of small pores, and the exposure at the fibre surface of well textured microfibrillar structures from the secondary $\mathrm{S}$ wall (Han and Choi, 2010) (Fig. 5). At high irradiation doses (200-500 kGy), striations and cracks as well as the appearance of large pores are observed (Choi et al., 2009; Han et al., 2006b; Han and Choi, 2010; Takács et al., 1999, 2000). These morphological changes are associated with a decrease of the total surface area and roughness (Choi et al., 2009; Han et al., 2006b) which can be related to the strong degradation of the exposed secondary wall layers, the enlargement of micropores and the creation of numerous meso and macropores. It should be mentioned that pure cellulose substrates such as MCC also exhibit variations in specific surface area according to irradiation doses. Based on the congo red dye adsorption method, Driscoll et al. (2009) measured an increase of the specific surface area of MCC from $274 \mathrm{~m}^{2} / \mathrm{g}$ to $318 \mathrm{~m}^{2} / \mathrm{g}$ at $1000 \mathrm{kGy}$. Considering the simplest and non-layered microstructure of such cellulose substrate, only a regular increase of the specific surface area was
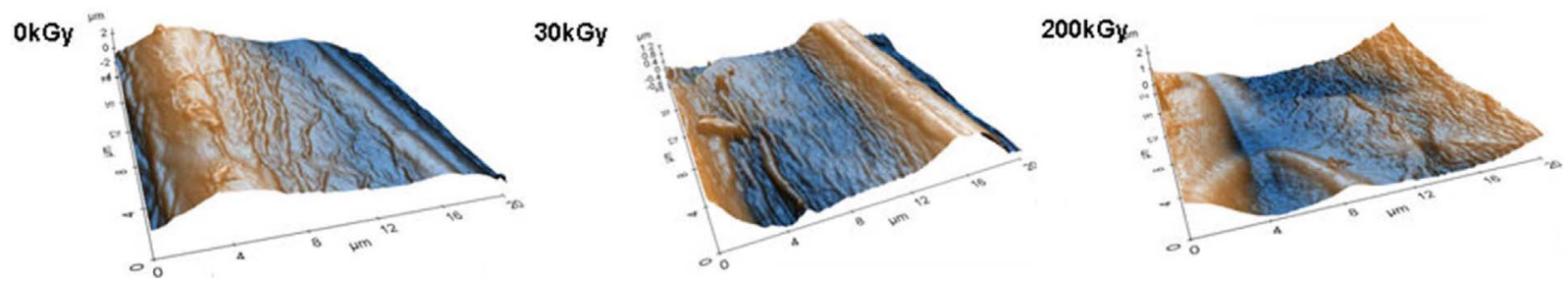

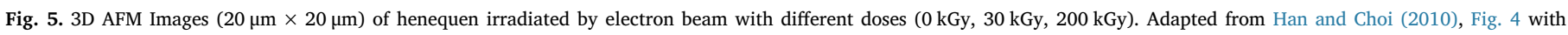
permission from Formatex Research Center. 
observed in this case.

These morphological modifications are accompanied by changes in the functional groups present at the fibre surface, caused by the irradiation of surface components and their oxidation and/or their removal. Although chemical surface modifications induced by physical treatments such as plasma or corona have been well investigated (Belgacem et al., 1995; Belgacem and Gandini, 2005), much less is known about the effect of irradiation on the surface chemistry of natural fibres. Considering their complex biochemical and microstructural organization and the fact that the radiation-induced degradation occurs in the bulk of the fibres, but also through a layer-by-layer degradation process, the surface chemistry of the fibres should undergo large variations according to irradiation conditions and the fibre origins and characteristics. Han et al. (2006a) studied by XPS the surface modifications occurring during irradiation of henequen fibres. They observed a decrease of hydrophobic carbon atoms and an increase of more hydrophilic carbon atoms and oxygen atoms on the surface of henequen fibres irradiated in the range $30 \mathrm{kGy}$ to $500 \mathrm{kGy}$. This was explained by the removal of waxes and impurities from the fibre surface at low irradiation doses and by the formation of O-containing functional groups on the fibre surfaces. Radiation-induced surface changes deserve to be further studied, especially at low irradiation doses for which significant but controllable surface modifications occur.

\subsection{Impact on physico-chemical, thermal and mechanical properties of natural fibres}

The radiation-induced molecular, microstructural and surface changes detailed above are responsible for significant modifications in the surface physico-chemistry, and the thermal and mechanical properties of natural fibres.

The hydrophobic/hydrophilic character undergoes significant variations according to the irradiation doses and the fibre characteristics. This has a direct effect on the water retention capacity of cellulosic fibre substrates. For rich-cellulose fibres such as cotton linters, it has been shown that the water retention value (WRV) increased from $41 \%$ to $64 \%$ after e-beam irradiation at $1500 \mathrm{kGy}$, and to $57 \%$ after gammairradiation at $250 \mathrm{kGy}$ (Klemm et al., 1998). The removal of weakly bonded components such as impurities and waxes present in raw natural fibres is also responsible for the formation of O-containing functional groups at their surface (Han et al., 2006a), which increases their hydrophilic character. Nevertheless, at low irradiation doses, the aforementioned crosslinking phenomenon can be responsible for a decrease of the water vapour sorption and water retention values (Borsa et al., 2003). Besides, improved hydrophobicity may also be achieved if lignin-carbohydrate complexes are formed by crosslinking upon irradiation (Lepifre et al., 2004). The effect of irradiation on the hydrophobic/hydrophilic character of natural fibres and its consequence on their water absorption and retention capacity thus depend on competitive phenomena that are intimately related to the irradiation conditions and fibre characteristics. At low irradiation doses, the removal of hydrophobic components from the fibre surface, responsible for an increase of hydrophilicity and water absorption, can be counterbalanced by cross-linking of some carbohydrate or lignin components which limit in turn the water absorption within the fibre structure. At high doses, the picture is simpler since the extensive degradation and depolymerisation undergone by the fibres offer a more accessible structure which increases undoubtedly their water absorption capacity. The variations in the porous structure and specific surface area described in the previous sections also play an important role in the water sorption properties.

The thermal stability of natural fibres is moderately affected by irradiation. The first thermal degradation step of kenaf and henequen fibres, occurring at $280-320^{\circ} \mathrm{C}$ and assigned to hemicelluloses and short chain molecules, was less marked due to the prior degradation of all or part of these components upon irradiation (Han et al., 2006b,
2007). The main decomposition step corresponding to cellulose degradation occurring between $315^{\circ} \mathrm{C}$ and $400{ }^{\circ} \mathrm{C}$ is also affected by irradiation. Khan et al. (2006) observed a linear shift of the decomposition peak from $373{ }^{\circ} \mathrm{C}$ to $365^{\circ} \mathrm{C}$ for jute fibres irradiated up to $100 \mathrm{kGy}$. Similar results were found for irradiated henequen and kenaf fibres with a decrease of the decomposition temperature from $362{ }^{\circ} \mathrm{C}$ to $347{ }^{\circ} \mathrm{C}$ at $500 \mathrm{kGy}$ and from $360^{\circ} \mathrm{C}$ to $346^{\circ} \mathrm{C}$ at $500 \mathrm{kGy}$, respectively (Han et al., 2006b, 2007). An increase of the decomposed fractions in the range $200-360{ }^{\circ} \mathrm{C}$ was also measured for henequen and kenaf fibres (Han et al., 2006b, 2007). These early and enlarged thermal degradations were explained by the presence of lower molecular weight compounds (Han et al., 2006b) and the partial degradation of the crystalline regions (Khan et al., 2006) that makes the irradiated fibres more sensitive to thermal degradation.

Several studies reported the effect of irradiation on the mechanical behaviour of natural fibres. Khan et al. (2006) observed a strong decrease of the tensile strength, elongation at break and work done at rupture $(22 \%, 16 \%$ and $38 \%$, respectively) for jute fibres with increasing gamma irradiation doses up to $50 \mathrm{kGy}$. In contrast, Takács et al. (2005) have observed that the tensile strength of cotton-cellulose is almost unchanged after irradiation at doses $10-40 \mathrm{kGy}$, while degree of polymerization drops from 1680 to 230 . Barbosa et al. (2012) found that at $50 \mathrm{kGy}$ the strength of buriti fibres can be even increased whereas at higher irradiation doses, i.e. $250 \mathrm{kGy}$ and $500 \mathrm{kGy}$, a drastic decrease of fibre strength was observed. This was attributed to structural damages within the cell walls and a totally brittle fracture was evidenced by SEM observations. Studying the thermomechanical properties of irradiated henequen fibre bundles by dynamic mechanical analysis, Han et al. (2006a) measured a decrease of the storage modulus over a wide temperature range $\left(-20^{\circ} \mathrm{C}\right.$ to $\left.240{ }^{\circ} \mathrm{C}\right)$ with increasing irradiation doses. At $200{ }^{\circ} \mathrm{C}$, the authors also noticed an early breakage of the fibres irradiated at $200 \mathrm{kGy}$. Arthur (Arthur, 1971) reported a relationship between the number of chain breaks per cellulose molecule and the breaking strength of random fibrous cellulose substrates. The breaking strength was found to be constant up to 15-20 chain breaks per molecule, while above $50-60$ chain breaks, no significant strength remained. Bouchard et al. (2006) established a linear relationship between the zero-span tensile strength (related to average fibre strength) of irradiated cotton paper and the chain scission number irrespective of the electron beam energy (Fig. 6a). As already mentioned, they also found a linear relationship between the irradiation dose and the chain scission number. These results thus suggest that the cotton paper strength loss consecutive to irradiation is proportional to the number of breakdown in cellulose chains as well as the radiation dose. Similar results were found by Muto et al. (1995) for cotton, abaca and bleached kraft hardwood handsheets and by Khan et al. (2006) for jute fibres. The authors also assumed that the loss of mechanical properties of jute fibres was caused by the radiation-induced chain scissions. Unlike the work of Bouchard et al. (2006) conducted on cotton paper, Khan et al. (2006) showed that the decrease in the mechanical properties of jute fibres is non-linear, and can be well fitted by a modified Arrhenius equation, attesting that jute fibre degradation during irradiation occurs through a first-order reaction process (Fig. 6b). Besides, it should be mentioned that few studies reported that crosslinking and the extent of intermolecular bonding occurring at low irradiation doses can lead to a slight increase of the breaking strength (Arthur, 1971) and the crease resistance (Takács et al., 1999) of cotton fibres.

\subsection{Concluding remarks on radiation-induced modifications in natural fibres}

Changes in natural fibres upon irradiation primarily proceed through depolymerisation, crosslinking, inter-molecular bonding and oxidation mechanisms that are intimately related to the irradiation conditions. These phenomena have a strong impact on the microstructure and surface properties of natural fibres, and greatly influence 

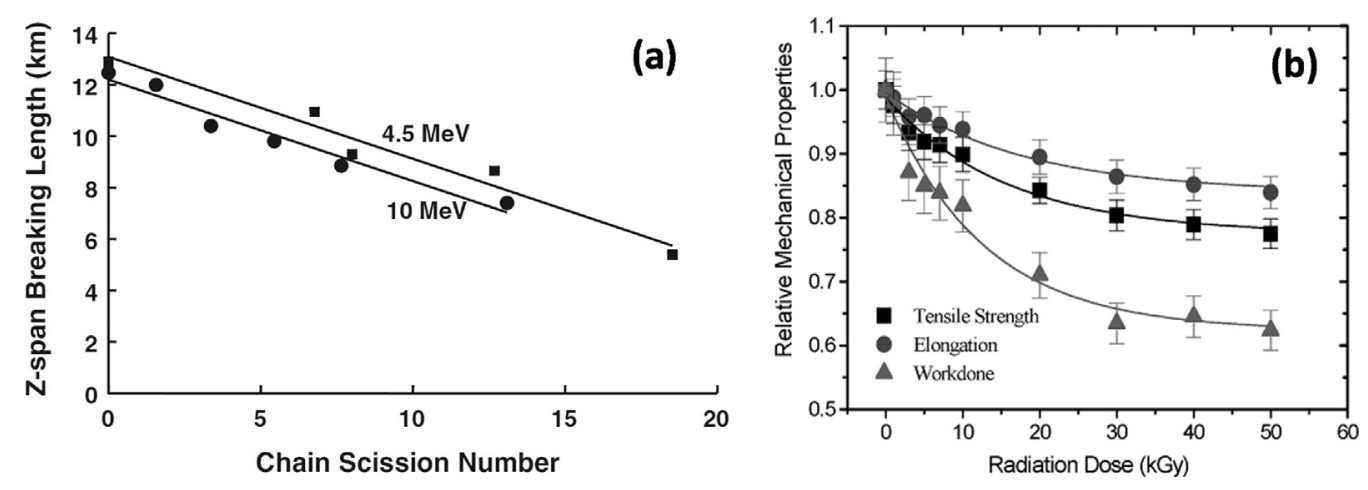

Fig. 6. (a) Linear relationship between Zspan strength and chain scission number for cotton paper irradiated at two level of electron energy (4.5 and $10 \mathrm{MeV}$ ) and (b) Relative mechanical properties of jute fibers plotted as a function of radiation dose (samples irradiated in air at $1.0 \mathrm{kGy} / \mathrm{h}$ ). Reprinted from (a) Bouchard et al. (2006), Fig. 4 with permission from Springer and (b) from Khan et al. (2006), Fig. 1, Copyright (2017) American Chemical Society.

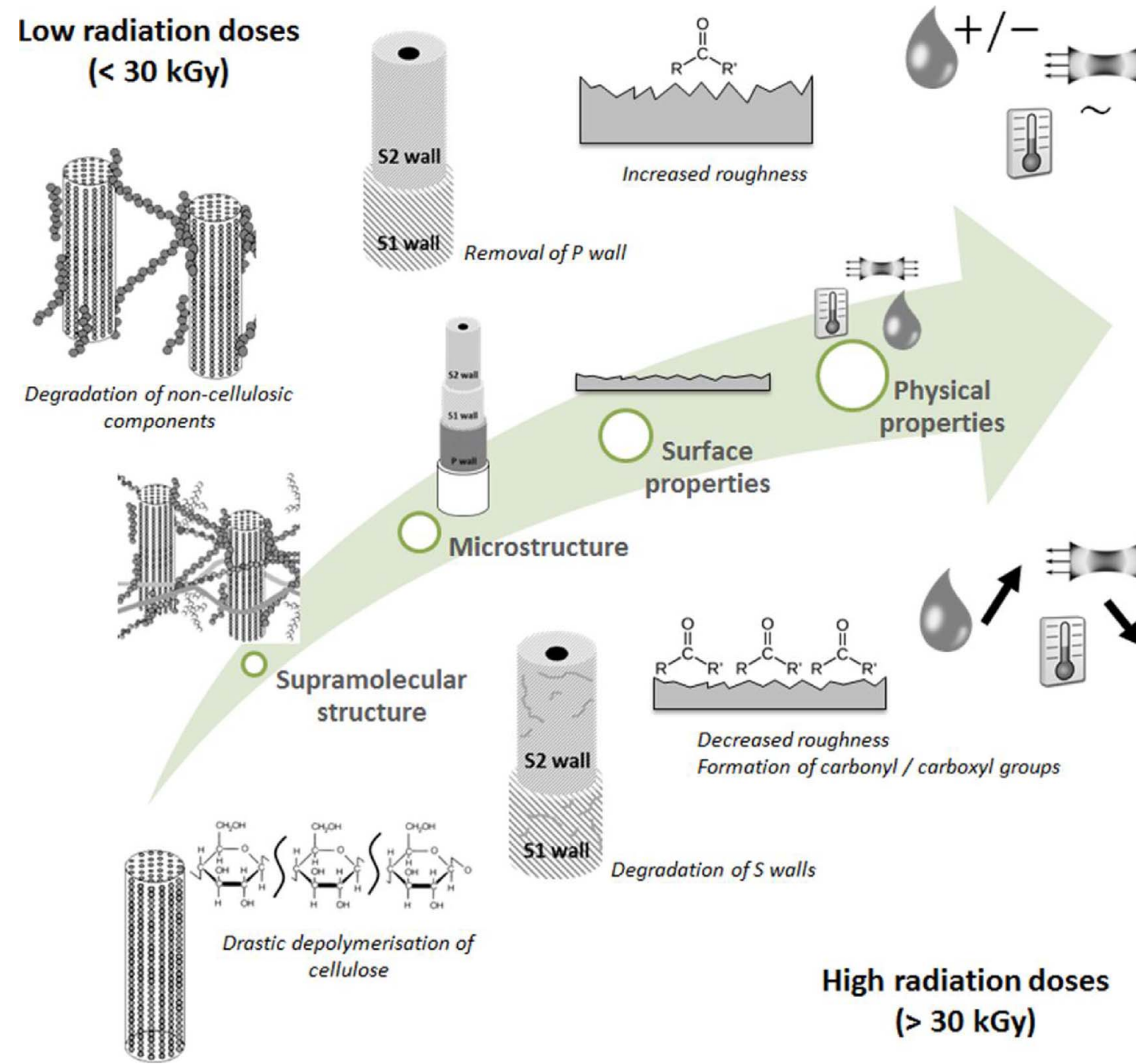

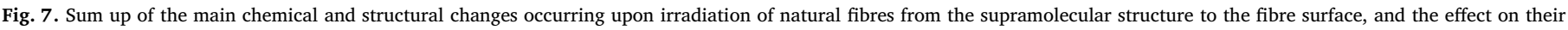
physical properties.

their physical properties. Based on observations and characterizations reported in literature, Fig. 7 proposes a sum up of the main molecular, microstructural and surface changes occurring at low and high irradiation doses, and their consequences on fibre physical properties. It is worth mentioning that at low radiation doses ( $<30 \mathrm{kGy}$ ), natural fibres undergo limited degradation, while tailored surface properties in terms of physico-chemistry and topography can be obtained by controlling the radiation conditions according to cellulose substrates. As will be discussed in the following sections, these radiation-induced modifications also have a strong influence on the behaviour of natural fibre reinforced biocomposites, hence giving new insights for the control of their properties.

\section{Effect of irradiation on the properties of natural fibre reinforced biocomposites}

Mechanical properties of natural fibres reinforced composites are significantly lower than those of their counterparts containing glass fibres (Faruk et al., 2014; Paramasivan and Abdul Kalam, 1974), despite natural fibres exhibit interesting mechanical performances (Faruk 
et al., 2012; Kozlowski and Wladyka-Przybylak, 2008). Indeed, specific Young's modulus of some natural fibres (hemp, flax) is higher than glass fibres (Kozlowski and Wladyka-Przybylak, 2008). The limited performances of biocomposites are in particular attributed to the poor interfacial adhesion between polar fibres and non- (or less-) polar polymer matrices. Nevertheless, there are some interesting exceptions. Joseph et al. (2002) have compared phenol formaldehyde composites reinforced with banana fibres or glass fibres. The average moduli of banana and glass fibres are respectively 12 and $65 \mathrm{GPa}$. In the whole, mechanical (tensile, flexural and impact) properties are higher with glass fibres, particularly when the fibre loading exceeds $30 \mathrm{wt} \%$. However, the authors note that the interfacial shear strength (measured using single fibre pull out test) is much higher for the composites reinforced with banana fibre (44 MPa versus $7 \mathrm{MPa}$ for glass fibres). Xu et al. (2012) have studied poly(lactic acid) PLA composites reinforced by ramie fibres. They found that ramie fibres provide very effective improvement of tensile properties, comparable to glass fibres at the same loading. These interesting performances are ascribed to various phenomena: strong alignment of ramie fibres during injection moulding, high crystallinity of PLA due to heterogeneous nucleation by fibres and naturally occurring interactions between fibres and PLA chains. These examples show that many parameters must be considered to assess the performances of biocomposites, and interfacial shear strength between natural fibres and matrix is not necessarily the weak point of biocomposites.

In the following, the influence of radiation on natural fibres reinforced composites is reviewed. We focused specifically on lignocellulosic fibres reinforced composites. However, when needed, references to proteinic (silk) or organic synthetic (aramid) fibres are also discussed. Reviews about the surface modification of natural fibres to improve properties of biocomposites have rarely mentioned ionizing irradiation as suitable method (Faruk et al., 2012; Kalia et al., 2009; Li et al., 2000; Mishra et al., 2004; NabiSaheb and Jog, 1999). Nevertheless several researchers have investigated the potential use of ebeam and gamma irradiation on biocomposites, either to improve the fibre-matrix adhesion and the mechanical properties, or to study the radiative ageing of these composite materials (Phiriyawirut et al., 2008; Shubhra et al., 2010; Varghese et al., 1994). Different strategies were tested either by the direct irradiation of the biocomposites or by the prior irradiation of the matrix and/or the natural fibres before their compounding.

\subsection{Direct irradiation of natural fibre reinforced composites}

In general, the direct irradiation of biocomposites leads to a slight improvement of mechanical properties at relatively low radiation doses. Polypropylene (PP)/jute composites exhibit optimum impact strength, tensile and bending modulus and strength after $\gamma$-irradiation at $5 \mathrm{kGy}$ (Haydaruzzaman et al., 2009; Mina et al., 2013). Same observations were made for PP/NR/(proteinic) silk and PP/silk composites with an optimal $\gamma$-irradiation dose of 2.5 and $5 \mathrm{kGy}$, respectively (Shubhra et al., 2010; Shubhra and Alam, 2011). The thermal stability of PP/ sisal, measured from the activation energy of anaerobic pyrolysis, also showed an optimum value for relatively low $\gamma$-radiation dose (25 kGy) (Albano et al., 2001). Ferreira et al. (2014) have found that mechanical (tensile and impact) properties of High Density Polyethylene (HDPE)/ piassava fibre $70-30 \mathrm{w} / \mathrm{w}$ are improved after e-beam irradiation even at high irradiation dose (200 kGy), maybe because crosslinking is prominent in HDPE. Same observations were made by Palm et al. (2015, 2016) with increases of modulus, ultimate strength and hardness, after irradiation of PE-based wood plastic composites (WPCs) up to $250 \mathrm{kGy}$. The authors assumed that crosslinking of polyethylene dominated the degradation of cellulosic wood fibres inherent to irradiation, thus explaining the improved mechanical performances of irradiated WPCs. Varghese et al. (1994) observed that changes in natural rubber/sisal composites after $\gamma$-irradiation depend on the mechanical property considered. For example, tensile strength increases up to $100 \mathrm{kGy}$ and decreases for higher doses. On the contrary, modulus for $10 \%$ elongation is maximum for $150 \mathrm{kGy}$. More surprisingly, the effect of radiation dose also depends on the fibre loading (between 6 and $24 \mathrm{wt} \%$ ) and on the use of a bonding agent (hexamethylenetetramine). Khan et al. have also observed an increase in mechanical properties and barrier properties of poly(caprolactone) PCL composites containing 2-10 wt\% of nanocrystalline cellulose (NCC) after $\gamma$-irradiation (10 kGy). These changes were assigned mainly to PCL crosslinking since the variation in properties was more significant for pure PCL. The authors assume that NCC may hinder the crosslinking of PCL (Khan et al., 2013).

Nevertheless, it is often difficult to ascertain the respective contributions of the matrix, the natural fibre modifications or the fibrematrix interface. Qualitative SEM observations are often performed to conclude about the enhancement in interfacial adhesion consecutive to irradiation. For example, Shubhra and Alam (2011) have noted that the mechanical properties of PP/silk fibres can be improved by $\gamma$-irradiation, contrarily to those of PP/glass fibres (no change observed in the dose range studied - 0-10 kGy). The authors explained these results by the formation of new bonds between PP and silk fibres due to active sites generated by $\gamma$-irradiation.

\subsection{Incorporation of pre-irradiated natural fibres in biocomposites}

Several studies have investigated the effect of pre-irradiation of natural fibres on the properties of composite materials. Biocomposites based on various matrices with pre-irradiated natural fibres have been extensively studied by Seong Ok Han's team (Choi et al., 2009; Han et al., 2006a,b, 2007, 2008). Better performances were observed for specific radiation doses and the authors attempted to explain these results by fibre modifications induced by irradiation treatment. As discussed, irradiation leads to many chemical and morphological changes at the surface as well as in the bulk of the fibres, and it is quite difficult to ascribe composite performances to one specific modification. Obviously, fibre surface properties, especially chemical composition and roughness at the fibre surface, should play a key role in the fibre-matrix adhesion through chemical bonding and mechanical interlocking.

Haydaruzzaman et al. (2009) have compared three different pathways to treat $\mathrm{PP} / 50 \mathrm{wt} \%$ jute fabrics composites by irradiation so as to discriminate interfacial coupling effects. PP and/or jute fabrics were pre-irradiated in presence of oxygen before manufacturing the composites. Gamma-radiation doses ranged from 0 to $10 \mathrm{kGy}$. Higher mechanical properties were obtained when both PP and jute were preirradiated. On the contrary, lower performances were observed when only PP was irradiated. Slightly better results were reached with preirradiation of jute fabrics only. Reactions between radicals on PP and jute were proposed to explain these results through a better bonding between both phases. Nevertheless, the authors did not check if free radicals generated during pre-irradiation were still active during manufacturing. Long-life radicals have already been found in PP (Rivaton et al., 2004) and can react during further processing steps (Sonnier et al., 2010). As discussed in the previous sections, long-life radicals are also trapped in natural fibres and might become reactive during manufacturing.

Sgriccia et al. (2008) have compared epoxy/kenaf and epoxy/hemp composites. They assigned the lower flexural modulus of the latter to the greater presence of waxes at the surface of hemp fibres. Kenaf fibres exhibit higher content of cellulose and lignin at their surface, leading to better adhesion (hydroxyl groups of cellulose and lignin may react with epoxide groups in the epoxy resin). The atomic $[\mathrm{O}] /[\mathrm{C}]$ ratio at the surface of fibres as measured by XPS allowed confirming differences in chemical composition at the surface of hemp and kenaf, i.e. the [O]/[C] ratio was 0.45 for kenaf fibres versus only 0.27 for hemp fibres because of the higher amount of waxes. Han et al. (2006a) have pre-irradiated henequen fibres by electron beam and prepared PBS-based composites 


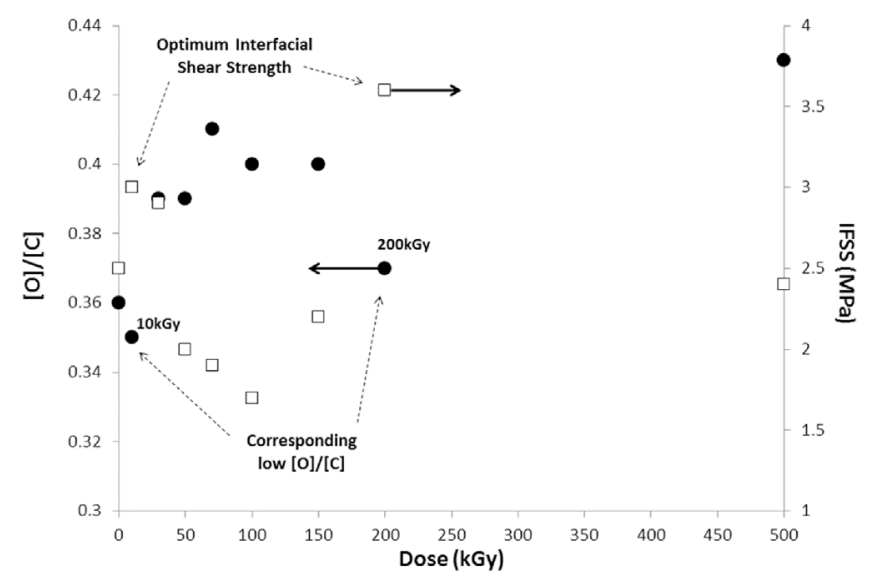

Fig. 8. Interfacial shear strength (IFSS) of $\mathrm{PBS} /$ henequen composites and $[\mathrm{O}] /[\mathrm{C}]$ ratio at the surface of henequen fibres versus the e-beam dose of fibre pre-irradiation (based on data in Han et al., 2006a).

containing $40 \mathrm{wt} \%$ of henequen fibres. Surface analysis of fibre was carried out by XPS. A microbonding test using a single fibre embedded into a crystallized PBS microdroplet was also performed to evaluate the interfacial adhesion between PBS and henequen fibres through the measurement of the interfacial shear strength (IFSS). IFSS values show two optima, for e-beam irradiation doses of 10 and $200 \mathrm{kGy}$ despite the continuous decrease of the fibre storage modulus when radiation dose increases. Moreover, from SEM observations of composites' fracture surfaces, the authors noted that fibre pull-out is less marked for henequen fibres pre-irradiated at these specific doses. The higher IFSS values were quite well correlated to low $[\mathrm{O}] /[\mathrm{C}]$ ratios at the henequen fibre surface, thus corresponding to more hydrophobic surfaces (Fig. 8). As discussed in the previous sections, the evolution of the surface hydrophobicity upon irradiation is related to many phenomena occurring according to the radiation dose: removal of waxes and impurities, formation of oxygen-containing functional groups, and alteration of these groups at higher doses, crosslinking between cellulose structures (rather at low doses), but also strong modifications of the fibre morphology at high doses. All these chemical and morphological changes are susceptible to have an influence on the fibre-matrix adhesion. Besides, it must be also noticed that the correlation between $[\mathrm{O}] /[\mathrm{C}]$ ratio and IFSS is not perfect (see for example values at 0 and $30 \mathrm{kGy}$ ).

Another interesting study concerns aramid fabrics/epoxy resin composites (Zhang et al., 2007). Aramid fibres are synthetic but still organic fibres. Therefore, $\gamma$-radiation was also used to modify and improve thermal and mechanical properties of the composites. The content of resin in the composites was assessed close to $38 \mathrm{wt} \%$. The interlaminar shear strength (ILSS) increased up to a strong radiation dose of $600 \mathrm{kGy}$. The mechanical properties of the fibres were not degraded at this dose but the surface oxygen content was enhanced (the ratio $[\mathrm{O}] /[\mathrm{C}]$ increased from 0.20 to 0.25 approximately), improving the wetting and bonding of fibres by the resin. Moreover, the fibre surface roughness was also enhanced by radiation, allowing better mechanical interlocking between aramid fabrics and the resin. The irradiation atmosphere had negligible influence: the ILSS increased by $17.7 \%$ when irradiation was carried out under nitrogen and $15.8 \%$ under air. Other authors have also made the same observations with natural fibres reinforced PP composites. Jute fibres topography turns from smooth to rough with lot of fractures after $10 \mathrm{kGy}$ irradiation, allowing a better mechanical bonding with PP matrix (Haydaruzzaman et al., 2009). Choi et al. (2009) have attempted to measure the pore structure of henequen fibres to explain the improved mechanical properties of irradiated henequen fibres/PP composites. The fibre content was $30 \%$ and radiation doses were ranged from 10 to $500 \mathrm{kGy}$ using an e-beam accelerator. The optimum mechanical properties (tensile strength and Izod impact strength) were found for a low radiation dose of $10 \mathrm{kGy}$.

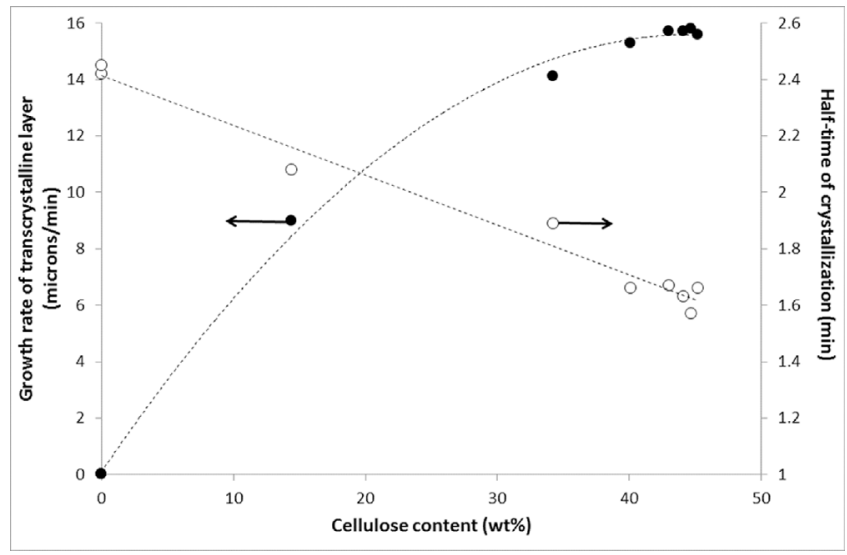

Fig. 9. Growth rate of the transcrystalline layer and half-time of crystallization according to cellulose content for $\gamma$-irradiated PP/wood composites (based on data in Borysiak, 2010).

The authors showed that low irradiation doses removed pectin, wax, lignin and the primary $\mathrm{P}$ wall of the fibres, hence creating many small pores. These small pores promote a better mechanical interlocking with the matrix. At higher doses ( $>10 \mathrm{kGy}$ ), radiation induced enlargement of small pores and the formation of mesopores and micropores, weakening in turn the mechanical properties. Nevertheless, the relation between mechanical performances of composites and porous structure of fibres was not fully evidenced. Indeed, the fibres themselves were also degraded by irradiation which modifies their mechanical properties and affects composite performances.

In semi-crystalline thermoplastic composites containing fibres, the formation of a transcrystalline layer can significantly influence the interfacial shear transfer between fibres and matrix. The extent of the transcrystalline zone depends on the nucleating ability of the fibres towards the matrix, which is related to the topography and surface chemical composition of lignocellulosic fibres. Borysiak (2010) has studied PP/wood composites $\gamma$-irradiated up to $9000 \mathrm{kGy}$. Irradiation leads to a decrease in cellulose content particularly for doses higher than $120 \mathrm{kGy}$. This decrease results in a lower growth rate of the transcrystalline layer and a higher half-time of crystallization (Fig. 9). In another study, Borysiak (2013) showed that the transcrystallinity extent can be modified by various chemical or radiation pre-treatments on wood fibres. These treatments had a great influence on the mechanical properties of $\mathrm{PP} /$ wood composites, even if it is difficult to discriminate the respective effects of transcrystallinity and intrinsic mechanical properties of wood fibres. Indeed, high radiation doses are needed to decrease the cellulose content and to prevent the transcrystallinity but it also decreases significantly the mechanical properties of the fibres. Besides, the surface chemical composition, especially the cellulose surface content, can be a relevant parameter to explain changes in mechanical properties when comparing composites reinforced with different types of natural fibres.

Other parameters controlling the mechanical performances can be listed. Intrinsic mechanical properties of natural fibres are important. As exposed in the first part of this review, irradiation can induce drastic deterioration of these properties. Nevertheless, it appears that intrinsic fibre properties are not necessarily predominant and that the quality of the interface is of primary importance. For example, as seen above (Han et al., 2006a), e-beam irradiation leads to a decrease of henequen storage modulus, whereas best interfacial shear strength values were obtained for high radiation dose (200 kGy). Improvement of composite properties was also found when fibres were pre-irradiated at $200 \mathrm{kGy}$ in the case of PP/kenaf, PP/henequen, unsaturated polyester (UP)/kenaf, UP/henequen (Han et al., 2006b, 2007, 2008). Obviously, composite performances are also strongly dependent on fibre dispersion. Khan and Khan reported that $\gamma$-irradiated jute fibres are better dispersed into PP 
matrix (Khan and Khan, 2009). On the contrary, untreated fibres tend to remain agglomerate into fibre bundles, and are unevenly distributed due to strong hydrogen bonds and interactions between elementary fibres.

Finally, water absorption by hydrophilic natural fibres can lead to interfacial delamination and drastic decrease of the mechanical properties of composites. Although pre-treatments of fibres by grafting suitable molecules allow limiting water absorption, irradiation by itself can also modify the ability of fibres and composites to absorb moisture (Sreekala and Thomas, 2003). Zaman et al. (Zaman et al., 2012) have studied PP/jute composites. PP and jute fibres were $\gamma$-irradiated with low doses (up to $10 \mathrm{kGy}$ ) before processing. Composites were prepared by stacking alternatively 4 layers of jute fibres and 5 layers of PP. The jute content was $45 \mathrm{wt} \%$. Water uptake was measured by soaking composites in deionized water at room temperature during 30 days. The pre-irradiation allows reducing the water uptake from nearly $14-8 \%$. Nevertheless, it is not clear if this improvement should be assigned to the jute fibres or PP modification through crosslinking or to a better interfacial adhesion between matrix and fibres. Haydaruzzaman et al. (2009) have also observed that water uptake at room temperature of $\mathrm{PP} /$ jute composites decreases when PP and jute fibres are pre-irradiated at $5 \mathrm{kGy}$. Once again, the respective modifications of jute fibres and PP during irradiation as well as the possible interfacial grafting cannot be discriminated. Sreekala et al. (Sreekala et al., 2002) have surfacetreated oil palm fibres (including using $\gamma$-irradiation) before incorporation into a phenol formaldehyde resin. All treated fibres exhibit lower water uptake. Nevertheless, the composites containing these fibres have a higher water uptake than the composite containing untreated fibres. Only mercerization leads to a lower water uptake. The authors explain this apparent contradiction by the fact that the water sorption in the composites does not only proceed through the matrix and fibre structure but also through the matrix-fibre interface. Most treatments led to more hydrophobic fibres, reduced fibre-matrix interactions and then higher water sorption at the interface.

\subsection{Is the ionizing radiation a suitable method to modify natural fibres and improve the performances of biocomposites?}

Predominant chain cleavage of cellulose and non-cellulosic components due to their high sensitivity towards ionizing radiations led some researchers to consider that radiation is not a suitable method to modify the surface of cellulose fibres (Belgacem and Gandini, 2005). Nevertheless, this conclusion can be nuanced and the relevance of radiation grafting to modify natural fibres is questioned in this section.

First, the grafting of molecules on natural fibres needs low radiation doses (few kGy). As previously discussed, cellulose degradation can remain limited in this range of radiation dose. Significant amounts of various molecules can be grafted on cellulose substrates with doses lower than $20 \mathrm{kGy}$ : grafting yield is typically in the range 10-50\% (Khan, 2005; Kodama et al., 2014; Sharif et al., 2013; Sonnier et al., 2015; Takács et al., 2005, 2007) or even more (> 100-200\%) (Takács et al., 2005, 2007). In some cases, a significant grafting level can be reached even at lower doses (Kaur et al., 2010). Obviously grafting yield strongly depends on the molecule to be grafted (Takács et al., 2005). Furthermore, Khan et al. have observed that the tensile strength and elongation at break of jute fibres show a limited decrease by 5 and $10 \%$, respectively, after $10 \mathrm{kGy}$ of $\gamma$-radiation under air (and 10 and $15 \%$ respectively after $20 \mathrm{kGy}$ ) (Khan et al., 2006). When interfacial strength is considered as the weak point within the composite, it can be interesting to improve the interfacial adhesion between fibres and matrix by radiation-grafting approaches, at the expense of a limited decrease of intrinsic mechanical properties of fibres.

There are two main routes to graft molecules or macromolecules onto a fibre using ionizing radiation (Roy et al., 2009): (i) the first pathway is called pre-irradiation and can be used for "grafting-to" method: the fibre is first irradiated and the solution containing the (macro) molecule to be grafted is then added. The grafting occurs thanks to the radicals already formed on the fibre during irradiation (Mohamed et al., 2013; Sharif et al., 2013); (ii) the second pathway is known as the mutual grafting and can be used for "grafting-from" method: the fibre is impregnated with the molecule and then irradiated, leading to the grafting of the molecule on the fibre and its possible free radical polymerization (Kaur et al., 2010; Kodama et al., 2014; Sonnier et al., 2015). Desmet et al. (Desmet et al., 2011) consider that mutual grafting is less detrimental for cellulose because solvent and monomer can act as stabilizers during irradiation. Güven et al. (2016) suggested that the use of mixed solvent as water/ethanol can generate highly reactive $\mathrm{OH}$ radicals upon irradiation, resulting in the partial absorption of the radiation by the solvent mixture and protecting the biopolymers constituting natural fibres from degradation. However, one drawback of this method is the formation of homopolymer.

It is interesting to note that both methods allow reaching high degrees of grafting. Khan (2005) investigated the pre-irradiation method and determined the influence of atmosphere on the grafting yield of methyl methacrylate monomers onto jute fibres. They observed that the grafting yield was higher when the irradiation was performed in air rather than in nitrogen. This was explained by the conversion of some short-lived radicals into peroxides through reaction with oxygen. These long-lived peroxides can subsequently contribute to the grafting reaction. Note that Takács et al. (2005) have detected long-lived radicals in irradiated cellulose even after one-month's storage. Therefore grafting through pre-irradiation may be also partly due to these radicals and not only to peroxides. Solpan et al. (2010) have compared pre-irradiation and mutual grafting of 2-chloroacrylonitile on cellulose. They found that mutual grafting allows reaching generally higher grafting level than pre-irradiation method. Nevertheless, the pre-irradiation dose is a very influent parameter, and a balance should be found since the amount of created radicals could be too low at low radiation doses and cellulose degradation can be induced at high radiation dose. Solpan et al. (2010) determined an optimal dose around $18 \mathrm{kGy}$. At such a dose, and with the same monomer concentration (5\%), pre-irradiation and mutual grafting lead to similar grafting yields (around 10\%). Takacs's team confirmed that the grafting yield is one order of magnitude higher in the case of mutual grafting (Desmet et al., 2011; Takács et al., 2007). They found optimal conditions for glycidyl methacrylate grafting onto cellulose. Due to higher efficiency, mutual grafting can occur at lower dose (avoiding cellulose degradation) with lower monomer concentration (Desmet et al., 2011). Kaur et al. have also observed that mutual grafting of acrylic acid on rayon fibres is the highest for a moderate dose (around 1 kGy) (Kaur et al., 2010). At higher doses, the grafted chains undergo chain scission leading to a lower grafting yield. In the same study, the authors have compared ionizing radiation route and a chemical method based on a ceric ion redox system to graft acrylic acid onto cellulose. They concluded that radiation method is more suitable than the chemical method. Indeed, a slightly higher grafting yield was reached under milder reaction conditions using a lower concentration of acrylic acid. The authors also observed that the fibres grafted using radiation were more thermally stable. Their initial decomposition temperature was increased by $30{ }^{\circ} \mathrm{C}$ in comparison to the fibres grafted using the chemical method.

The presence of lignin appears to have a strong influence on grafting efficiency. Several studies report that high degree of grafting can be reached when using delignified fibres. Sharif et al. (2013) have measured the radiation-grafting of glycidyl methacrylate onto partially delignified kenaf fibres. They found that the grafting level decreases when the lignin content increases (Fig. 10). Mohamed et al. have also confirmed these results when they attempted to graft 4-chloromethyl styrene onto delignified kenaf fibres (Mohamed et al., 2013). However, Ali Ayoub et al. have shown that lignin can be grafted by styrene monomer at low doses (Ayoub et al., 2014). Styrene fraction in grafted lignin reaches around $10 \%$ for radiation doses ranging between 5 and $50 \mathrm{kGy}$ when the initial styrene content was fixed at $13 \%$. It should be 


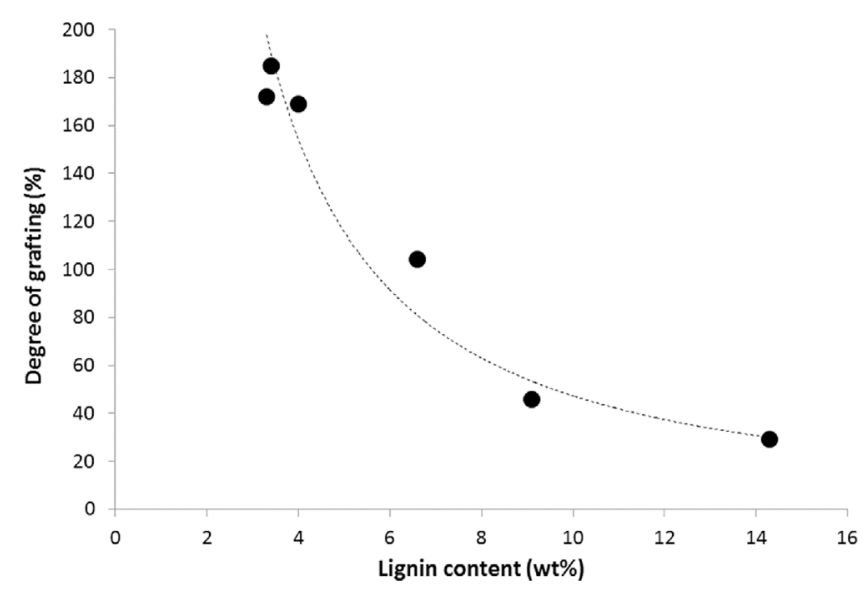

Fig. 10. Degree of glycidyl methacrylate grafting onto kenaf fibres versus lignin content (based on data in Sharif et al., 2013).

noted that, in this study, mutual grafting was chosen while Sharif et al. (2013) and Mohamed et al. (2013) used pre-irradiation method.

Second, radiation grafting is an easy way to fix a large amount of molecules into natural fibres. Indeed, natural fibres are very porous and susceptible to swelling. For these reasons, the dipping of natural fibres into a solution containing functionalizing molecules can lead to the huge penetration of molecules into the bulk. Subsequent irradiation allows fixing and/or crosslinking these molecules to the fibres. Even if the fibre/matrix interfacial shear strength generally needs a small amount of compatibilizing agent at the fibre surface, other functional properties can only be achieved with a high grafting level in the fibre bulk. Hence, Sonnier et al. have prepared flame retarded flax fabrics by radiation grafting of methyl vinyl phosphonate (MVP). Phosphorus content within the fibres reached 3-4 wt\% allowing self-extinguishment of flax fabrics, even at low radiation dose (10 kGy) (Sonnier et al., 2015). Flame retardancy of composites containing these fabrics was also improved. It must be noted that grafting of phosphorus molecules was needed to avoid their release in gaseous phase at too low temperatures. Benke et al. have also pointed out the role of cellulose accessibility on the grafting yield. The accessibility depends on the cellulosic substrate, the monomer to be grafted and the solvent (Benke et al., 2007). Desmet et al. (2011) also consider that grafting may occur mainly on the surface in case of mutual grafting while it may be more homogeneous in the fibre bulk for pre-irradiation.

Ionizing radiation allows generating radicals onto the surface and in the bulk of lignocellulosic substrates. But in the previously cited works, the control of grafting and polymerization was rather poor. Hence, in the study of Sonnier et al. (2015), the length of poly(methyl vinyl phosphonate) MVP chains grafted to flax fibres has not been measured but the distribution of chain length was probably highly scattered. Nevertheless, it is possible to have an excellent control of grafting using other methods initiated by irradiation. Indeed, in a series of papers, Barsbay et al. have studied the grafting and polymerization of styrene and sodium 4-styrenesulfonate from cellulose by radiation-induced RAFT (reversible addition-fragmentation chain transfer) polymerization (Barsbay et al., 2007; Barsbay and Güven, 2009; Barsbay et al., 2009). $\gamma$-radiation generates radicals inducing initiation of the monomer polymerization, which is well controlled by the RAFT technique. The molecular mass of grafted chains increases linearly with monomer conversion and the polydispersity is narrow. As discussed by Güven et al. (2016), when considering solvent-mediated graft copolymerisation, the solvent used in the grafting mixture is likely to enhance the ease monomer diffusion, and hence reduce monomer consumption and homopolymerisation.

As briefly exposed in this section, ionizing irradiation offers flexibility and several advantages as a grafting method to functionalize natural fibres and potentially improve functional properties of biocomposites.

\section{Industrial feasibility and costs of radiation induced modifications}

Currently, industrial processes for polymeric material improvement, based on radiation chemistry, include: polymerization, grafting under irradiation or post-irradiation, crosslinking, degradation, cyclization, radiation resistance and preparation of composite materials (Drobny 2013; Ferry et al., 2016; IAEA, 2002, 2003, 2008, 2009, 2016; Makuuchi 2012; Rouif, 2004; Sonnier et al., 2012). Four main technologies developed at the industrial scale enable to achieve such processes:

- Low and medium energy electron beam (150 keV-5 MeV electron accelerators),

- High energy electron beam (10 MeV) adapted to parcels,

- Gamma rays from Cobalt-60 (highly penetrating rays) for the treatment of parcels, pallets, bobbins ...

- X-Rays units also for the treatment of pallets.

In the seventies, radiation processing of polymeric materials was essentially performed with electron accelerators of low or medium energy, allowing only surface treatments and limited to a few millimeters of depth. This technology was particularly adapted to linear or 2-dimensionnal products (pipes, packaging film, textiles ...). High-energy electron accelerators $(10 \mathrm{MeV}$ ) and Gamma rays (strong capacity of penetration of the radiation), whose implantations have expanded in the eighties, and X-Rays facilities developed since 2000, allow the treatment of larger products thicknesses of the size of a cardboard box (several centimetres) up to a pallet $(1 \mathrm{~m})$. Thereby, these technologies enable the radiation processing of moulded plastic parts, directly in their packaging, and of complete bobbins or big bags (Fig. 11).

All these technologies continue to expand worldwide in different technological and scientific research institutes, supported by (i) the presence of almost 200 gamma implantations in the world (IAEA, 2004), (ii) the growing implantation of electron accelerators, as for example: more than three hundred in Japan and almost 650 in North America between 1970 and 1998 (Makuuchi and Cheng, 2012), and more than four hundred in China since 2000 (Zhang, 2016), and (iii) the recent development since 2001 of X-ray facilities dedicated to large batches (about ten units now worldwide).

As discussed in paragraph 3, in the case of lignocellulosic substrates, it is preferable to work in the dose range of $1-50 \mathrm{kGy}$, and more preferably not more than $30 \mathrm{kGy}$ because of secondary reactions as biopolymers chain scissions that can drastically degrade the original properties of natural fibres and resulting performances of their biocomposites. In this range of dose, serial industrial treatment will be less than $1 \$ / \mathrm{kg}$ of radiated material, and in case of large delivered volumes, price of $0.3 \$ / \mathrm{kg}$ of radiated material can be achieved. Such low price levels are favourable to the economic feasibility of radiation processing of natural fibres. Although radiation costs are dose dependent, in the dose range $<30 \mathrm{kGy}$, prices are quite independent from the dose, because they are mainly steered by invariable operational costs.

\section{Conclusions}

In this review, the impact of irradiation on the properties of natural fibres and their biocomposites was detailed. Changes in natural fibre structure upon irradiation primarily occur through depolymerisation, crosslinking, inter-molecular bonding and oxidation mechanisms that are intimately related to the irradiation conditions. These phenomena have a strong impact on the microstructure and surface properties of natural fibres, and greatly influence their physical properties. At low radiation doses ( $<30 \mathrm{kGy}$ ), natural fibres undergo limited degradation 

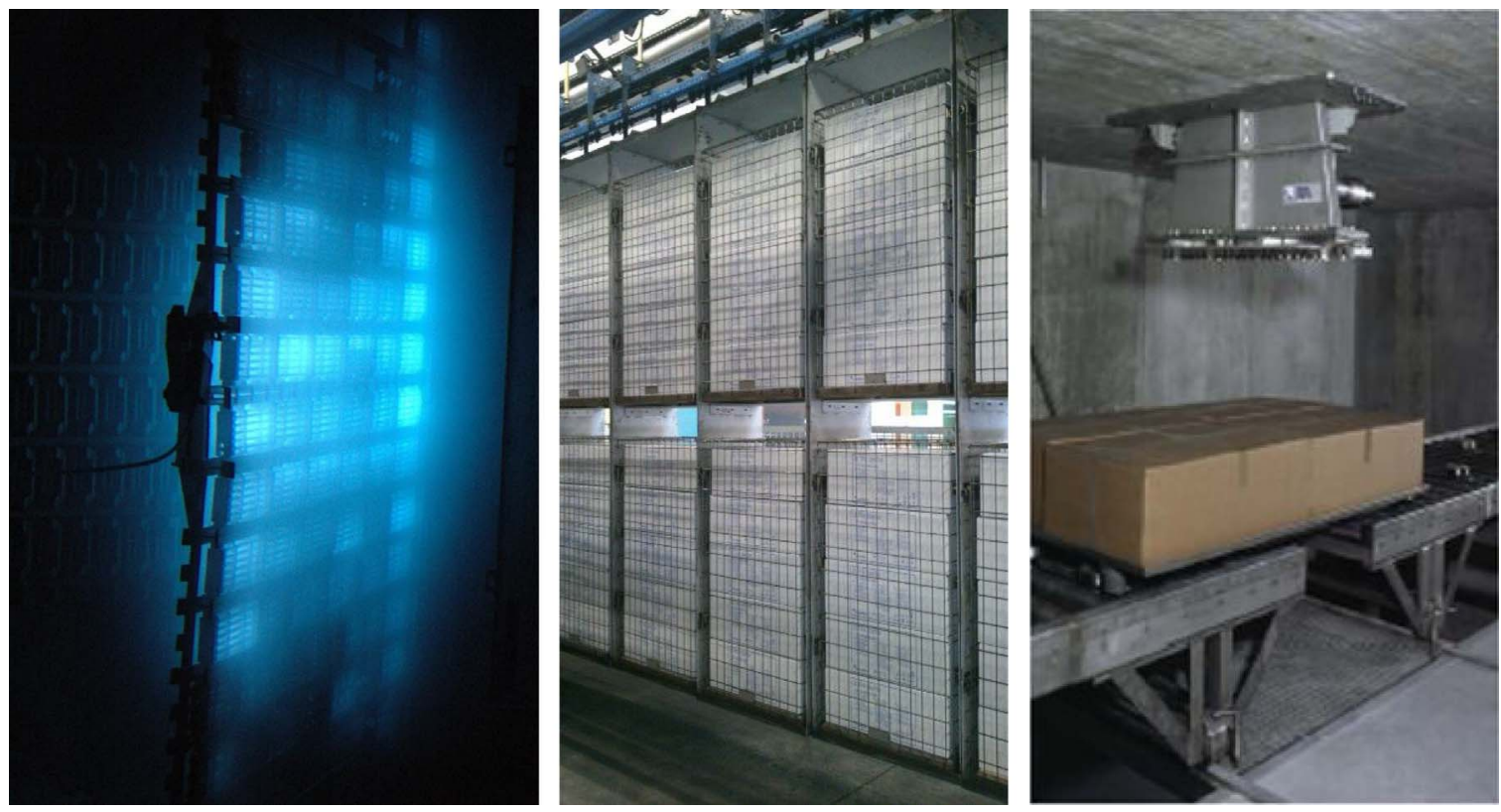

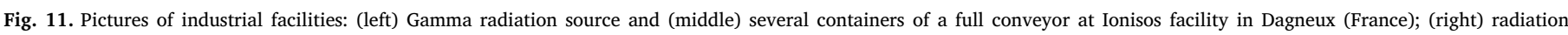
treatment of a pallet layer at Ionisos facility in Tarancon (Spain). Copyright (2017) Ionisos SAS.

with a good preservation of their thermal and mechanical properties, while tunable surface properties in terms of physico-chemistry and topography, can be obtained by controlling the radiation conditions according to lignocellulosic substrates. At higher radiation doses, drastic degradation of cellulose and non-cellulosic components as well as the creation of large defects within the microstructure, strongly affects thermal and mechanical properties of natural fibres. Higher hydrophilicity is also observed.

The number of reports about the performances of composites reinforced by pre-irradiated natural fibres is rather limited. Irradiation seems to be able to improve the interfacial adhesion between the fibres and the matrix and to limit the water uptake of biocomposites. Nevertheless, these improvements were achieved in some cases at relatively high doses, leading to numerous chain scissions in cellulose but also other strong morphological modifications. In these conditions, the intrinsic properties of the fibres are highly impacted, and hence their role as reinforcement is doubtful.

On the other hand, low radiation doses can be acceptable without leading detrimental modifications of fibres. Besides, such low doses are efficient enough to graft molecules onto (and also in the bulk) of natural fibres. Based on this review of literature, we assume that a narrow but suitable range of irradiation doses allows radiation-grafting on natural fibres while maintaining their overall integrity and physical properties. Moreover, radiation-grafting offers some advantages over other chemical and physical treatment methods. In particular, high grafting yield can be reached quickly without heating, which is of great interest for natural fibres being thermally sensitive. Based on these facts, ionizing radiation methods used in suitable and controlled conditions are relevant over other physical and chemical methods developed for the surface modification and functionalization of bio-reinforcements in composite applications.

\section{Acknowledgement}

The authors acknowledge the French Fonds Unique Interministériel (FUI) and the Pôles de Compétitivité Axelera, IAR, Plastipolis and Techtera for supporting the BIONICOMP project.

\section{References}

Albano, C., Reyes, J., Ichazo, M., Gonzalez, J., Chipara, M., 2001. Influence of gamma irradiation on the thermal stability of blends and PP with previously treated sisal fiber. Polym. Degrad. Stab. 73, 225-236.

Argyropoulos, D.S., Menachem, S.B., 1998. Lignin. In: Kaplan, D.L. (Ed.), Biopolymers from Renewable Resources. Springer, Berlin, Heidelberg, pp. 292-322.

Arthur, J.C., 1971. Reactions Induced by high-energy radiation. In: 2nd ed. In: Bikales, N.M., Segal, L. (Eds.), High Polymers: Cellulose and Cellulose Derivatives Vol. V. Part V Wiley-Interscience, New York, pp. 937-975.

Atchison, J.E., 1983. Data on non-wood plant fibers. In: Kocurek, M.J. (Ed.), Pulp and Paper Manufacture, 1 Properties of Fibrous Raw Materials and Their Preparation for Pulping. Tappi Press, Atlanta, GA (XVII).

Ayoub, A., Venditti, R., Jameel, H., Chang, H.-M., 2014. Effect of irradiation on the composition and thermal properties of softwood kraft lignin and styrene grafted lignin. J. Appl. Polym. Sci. 131, 39743-39753.

Barbosa, A.P., Costa, L.L., Portela, T.G.R., Moura, E.A.B., Del Mastro, N.L., Satayanarayana, K.G., Monteiro, S.N., 2012. Effect of electron beam irradiation on the mechanical properties of buriti fiber. Materia 17, 1135-1143.

Barsbay, M., Güven, O., 2009. A short review of radiation-induced raft-mediated graft copolymerization: a powerful combination for modifying the surface properties of polymers in a controlled manner. Radiat. Phys. Chem. 78, 1054-1059.

Barsbay, M., Güven, O., Stenzel, M., Davis, T., Barner-Kpwollik, C., Barner, L., 2007. Verification of controlled grafting of styrene from cellulose via radiation-induced RAFT polymerization. Macromolecules 40, 7140-7147.

Barsbay, M., Güven, O., Davis, T., Barner-Kowollik, C., Barner, L., 2009. RAFT-mediated polymerization and grafting of sodium 4-styrenesulfonate from cellulose initiated via $\gamma$-radiation. Polymer 50, 973-982.

Belgacem, M.N., Gandini, A., 2005. The surface modification of cellulose fibres for use as reinforcing elements in composite materials. Compos. Interfaces 12, 41-75.

Belgacem, M.N., Czeremuszkin, G., Sapieha, S., Gandini, A., 1995. Surface characterization of cellulose fibres by XPS and inverse gas chromatography. Cellulose 2, 145-157.

Benke, N., Takács, E., Wojnarovits, L., Borsa, J., 2007. Pre-irradiation grafting of cellulose and slightly carboxymethylated cellulose (CMC) fibres. Radiat. Phys. Chem. 76, 1355-1359.

Bismarck, A., Aranberry-Askargorta, I., Springer, J., Lampke, T., Wielage, B., Stamboulis, A., Shenderovich, I., Limbach, H.-H., 2002. Surface characterization of flax: hemp and cellulose fibers surface properties and the water uptake behaviour. Polym. Compos. 23, 872-894.

Borsa, J., Tóth, T., Takács, E., Hargittai, P., 2003. Radiation modification of swollen and chemically modified cellulose. Radiat. Phys. Chem. 67, 509-512.

Borysiak, S., 2010. A study of transcrystallinity in polypropylene in the presence of wood irradiated with gamma rays. J. Therm. Anal. Calorim. 101, 439-445.

Borysiak, S., 2013. Fundamental studies on lignocellulose/polypropylene composites: effects of wood treatment on the transcrystalline morphology and mechanical properties. J. Appl. Polym. Sci. 127, 1309-1322.

Bouchard, J., Méthot, M., Jordan, B., 2006. The effects of ionizing radiation on the cellulose of woodfree paper. Cellulose 13, 601-610.

Brosse, N., El Hage, R., Sannigrahi, P., Ragauskas, A., 2010. Dilute sulfuric acid and ethanol organosolv pretreatment of Miscanthus x Giganteus. Cellul. Chem. Technol. 44, 71-78.

Brosse, N., Dufour, A., Meng, X., Sun, Q., Ragauskas, A., 2012. Miscanthus: a fast- 
growing crop for biofuels and chemicals production. Biofuels Bioprod. Biorefin. 6 , $580-598$

d'Amour, J., Gosselin, C., Arul, J., Castaigne, F., Willemot, C., 1993. Gamma-radiation affects cell wall composition of strawberries. J. Food Sci. 58, 182-185.

Choi, H., Han, S., Lee, J., 2009. The effects of morphological properties of henequen fiber irradiated by eb on the mechanical and thermal properties of henequen fiber/PP composites. Compos. Interfaces 16, 751-768.

Desmet, G., Takacs, E., Wojnarovits, L., Borsa, J., 2011. Cellulose functionalization via high-energy irradiation-initiated grafting of glycidyl methacrylate and cyclodextrin immobilization. Radiat. Phys. Chem. 80, 1358-1362.

Deyholos, M.K., Potter, S., 2014. Engineering bast fibre feedstocks for use in composite materials. Biocatal. Agric. Biotechnol. 3, 53-57.

Driscoll, M., Stipanovic, A., Winter, W., Cheng, K., Manning, M., Spiese, J., Galloway, R.A., Cleland, M.R., 2009. Electron beam irradiation of cellulose. Radiat. Phys. Chem. $78,539-542$.

Drobny, J.G., 2013. Ionizing Radiation and Polymers, Principles, Technology and Applications, Plastics Design Library. William Andrew Publishing, Oxford, USA.

Dubey, K.A., Pujari, P.K., Ramnani, S.P., Kadam, R.M., Sabharwal, S., 2004. Microstructural studies of electron beam-irradiated cellulose pulp. Radiat. Phys. Chem. 69, 395-400.

El Hage, R., Chrusciel, L., Desharnais, L., Brosse, N., 2010a. Effect of autohydrolysis of Miscanthus x giganteus on lignin structure and organosolv delignification. Bioresour. Technol. 101, 9321-9329.

El Hage, R., Brosse, N., Sannigrahi, P., Ragauskas, A., 2010b. Effects of process severity on the chemical structure of Miscanthus ethanol organosolv lignin. Polym. Degrad. Stab. 95, 997-1003.

Faruk, O., Bledzki, A., Fink, H.P., Sain, M., 2012. Biocomposites reinforced with natural fibers: 2000-2010. Prog. Polym. Sci. 37, 1552-1596.

Faruk, O., Bledzki, A., Fink, H.P., Sain, M., 2014. Progress report on natural fiber reinforced composites. Macromol. Mater. Eng. 299, 9-26.

Fengel, D., Wegener, G., 1989. Wood Chemistry, Ultrastructure and Reactions. Walter de Gruyter, Berlin.

Ferreira, M., Sartori, M., Oliveira, R., Guven, O., Moura, E.A.B., 2014. Short vegetal-fiber reinforced HDPE - a study of electron-beam radiation treatment effects on mechanical and morphological properties. Appl. Surf. Sci. 310, 325-330.

Ferry, M., Ngono-Ravache, Y., Aymes-Chodur, C., Clochard, M.C., Coqueret, X., Cortella, L., Pellizzi, E., Rouif, S., Esnouf, S., 2016. Ionizing radiation effects in polymers. Reference Module in Materials Science and Materials Engineering. Elsevier.

Fischer, K., Goldberg, W., 1987. Changes in lignin and cellulose by irradiation. Makromol. Chem. Macromol. Symp. 12, 303-322.

Fischer, K., Goldberg, W., Wilke, M., 1985. Strahlvorbehandlung von zellstoff für die regeneratfaserherstellung. Lenzinger Berichte 59, 32-39.

Foldváry, Cs. M., Takács, E., Wojnárovits, L., 2003. Effect of high-energy radiation and alkali treatment on the properties of cellulose. Radiat. Phys. Chem. 67, 505-508.

Güven, O., Monteiro, S.N., Moura, E.A.B., Drelich, J.W., 2016. Re-emerging field of lignocellulosic fiber - polymer composites and ionizing radiation technology in their formulation. Polym. Rev. 56 (4), 702-736.

Gutierrez, A., Rodriguez, I.M., del Rio, J.C., 2008. Chemical composition of lipophilic extractives from sisal (Agave sisalana) fibers. Ind. Crops Prod. 28, 81-87.

Han, S.O., Choi, H.Y., 2010. Morphology and surface properties of natural fiber treated with electron beam. In: Méndez-Vilas, A., Díaz, J. (Eds.), Microscopy: Science, Technology, Applications and Education. Formatex Research Center, pp. 1880-1887.

Han, S., Cho, D., Park, W., Drzal, L., 2006a. Henequen/poly(butylene succinate) biocomposites: electron beam irradiation effects on henequen fiber and the interfacial properties of biocomposites. Compos. Interfaces 13, 231-247.

Han, Y., Han, S., Cho, D., Kim, H., 2006b. Henequen/unsaturated polyester biocomposites: electron beam irradiation treatment and alkali treatment effects on the henequen fiber. Macromol. Symp. 245-246, 539-546.

Han, Y., Han, S., Cho, D., Kim, H., 2007. Kenaf/polypropylene biocomposites: effects of electron beam irradiation and alkali treatment on kenaf natural fibers. Compos. Interfaces 14, 559-578.

Han, Y., Han, S., Cho, D., Kim, H., 2008. Dynamic mechanical properties of natural fiber/ polymer biocomposites: the effect of fiber treatment with electron beam. Macromol. Res. 16, 253-260.

Haydaruzzaman Khan, R.A., Khan, M.A., Khan, A.H., Hossain, M.A., 2009. Effect of gamma radiation on the performance of jute fabrics-reinforced polypropylene composites. Radiat. Phys. Chem. 78, 986-993.

Heinze, T., Petzold-Welcke, K., van Dam, J.E.G., 2012. Polysaccharides: molecular and supramolecular structures. terminology. In: Navard, P. (Ed.), The European Polysaccharide Network of Excellence (EPNOE). Springer-Verlag, Wien, pp. 23-64.

Hendriks, A.T.W.M., Zeeman, G., 2009. Pretreatments to enhance the digestibility of lignocellulosic biomass. Bioresour. Technol. 100 (1), 10-18.

Hon, D.N.S., 1994. Cellulose: a random walk along its historical path. Cellulose 1, 1-25.

IAEA reports, 2002. Radiation synthesis and modification of polymers for biomedical applications (IAEA-TECDOC-1324). . http://www-pub.iaea.org/MTCD/Publications/ PDF/te_1324_web.pdf (Accessed 11 July 2017).

IAEA reports, 2003. Advances in radiation chemistry of polymers (IAEA-TECDOC-1420). http://www-pub.iaea.org/MTCD/publications/PDF/TE_1420_Web.pdf (Accessed 11 July 2017).

IAEA reports, 2004. Directory of gamma processing facilities in member states (IAEADGPF/CD). . http://www-pub.iaea.org/MTCD/publications/PDF/dgpf-cd/PDF/ Contents.pdf (Accessed 11 July 2017).

IAEA reports, 2008. Trends in radiation sterilization of health care products (STI/PUB/ 1313). . http://www-pub.iaea.org/MTCD/publications/PDF/Pub1313_web.pdf (Accessed 11 July 2017).

IAEA reports, 2009. Controlling of degradation effects in radiation processing of polymers
(IAEA-TECDOC-1617). . http://www-pub.iaea.org/MTCD/publications/PDF/te_ 1617_web.pdf (Accessed 11 July 2017).

IAEA reports, 2016. The radiation chemistry of polysaccharides (STI/PUB/1731). http://www-pub.iaea.org/MTCD/Publications/PDF/P1731_web.pdf (Accessed 11 July 2017).

Iller, E., Kukiełka, A., Stupińska, H., Mikołajczykc, W., 2002. Electron-beam stimulation of the reactivity of cellulose pulps for production of derivatives. Radiat. Phys. Chem. 63, 253-257.

Jarvis, M.C., 1984. Structure and properties of pectin gels in plant cell walls. Plant Cell Environ. 7, 153-164.

John, M.J., Anandjiwala, R.D., 2008. Recent developments in chemical modification and characterization of natural fiber-reinforced composites. Polym. Compos. 29, 187-207.

Joseph, S., Sreekala, M., Oommen, Z., Koshy, P., Thomas, S., 2002. A comparison of the mechanical properties of phenol formaldehyde composites reinforced with banana fibres and glass fibres. Compos. Sci. Technol. 62, 1857-1868.

Kalia, S., Kaith, B., Kaur, I., 2009. Pretreatments of naturel fibers and their application as reinforcing material in polymer composites - a review. Polym. Eng. Sci. 49, 1253-1272.

Kaur, I., Kumar, R., Sharma, N., 2010. A comparative study on the graft copolymerization of acrylic acid onto rayon fiber by a ceric ion redox system and a $\gamma$-radiation method. Carbohydr. Res. 345, 2164-2173.

Khan, M., Khan, R., 2009. Radiation processing of natural fiber reinforced polymer composites. In: Thomas, S., Pothan, L. (Eds.), Natural Fibre Reinforced Polymer Composites - from Macro to Nanoscale. Archives Contemporaines., pp. 380-416.

Khan, F., Ahmad, S.R., Kronfli, E., 2006. $\gamma$-radiation induced changes in the physical and chemical properties of lignocellulose. Biomacromolecules 7, 2303-2309.

Khan, R., Beck, S., Dussault, D., Salmieri, S., Bouchard, J., Lacroix, M., 2013. Mechanical and barrier properties of nanocrystalline cellulose reinforced poly(caprolactone) composites: effect of gamma radiation. J. Appl. Polym. Sci. 129, 3038-3046.

Khan, F., 2005. Characterization of methyl methacrylate grafting onto preirradiated biodegradable lignocellulose fiber by $\gamma$-radiation. Macromol. Biosci. 5, 78-89.

Klemm, D., Philipp, B., Heinze, T., Heinze, U., Wagenknecht, W., 1998. Comprehensive Cellulose Chemistry Vol. 1 Wiley-VCH, Weinheim.

Klemm, D., Heublein, B., Fink, H.-P., Bohn, A., 2005. Cellulose: fascinating biopolymer and sustainable raw material. Angew. Chem. Int. Ed. 44, 3358-3393.

Kodama, Y., Barsbay, M., Güven, O., 2014. Radiation-induced and RAFT-mediated grafting of poly(hydroxylethyl methacrylate) (PHEMA) from cellulose surfaces. Radiat. Phys. Chem. 94, 98-104.

Kovács, E., Keresztes, Á, 2002. Effect of gamma and UV-B/C radiation on plant cells. Micron 33, 199-210.

Kozlowski, R., Wladyka-Przybylak, M., 2008. Flammability and fire resistance of composites reinforced by natural fibers. Polym. Adv. Technol. 19, 446-453.

Krässig, H.A., 1993. Cellulose - structure, accessibility and reactivity. In: Huglin, M.B. (Ed.), Polymer Monographs 11. Gordon and Breach Science Publishers, Amsterdam.

Kuehn, N., Jacobasch, H.-J., Lunkenheimer, K., 1986. Zum Zusammenhang zwischen dem Kontaktwinkel zwischen Wasser und festen Polymeren und ihrem Zeta-Potential gegenüber wäßrigen Lösungen. Acta Polym. 37, 394-396.

Lepifre, S., Froment, M., Cazaux, F., Houot, S., Lourdin, D., Coqueret, X., Lapierre, C. Baumberger, S., 2004. Lignin incorporation combined with electron-beam irradiation improves the surface water resistance of starch films. Biomacromolecules 5 , 1678-1686.

Li, Y., Mai, Y., Ye, L., 2000. Sisal fibre and its composites: a review of recent developments. Compos. Sci. Technol. 60, 2037-2055.

Li, Q., Li, X., Jiang, Y., Xiong, X., Hu, Q., Tan, X., Wang, K., Su, X., 2016. Analysis of degradation products and structural characterization of giant reed and Chinese sitvergrass pretreated by 60Co gamma-irradiation. Ind. Crops Prod. 83, 307-315.

Lilholt, H., Lawther, J.M., 2000. Natural organic fibres. In: In: Kelly, A., Zweben, C. (Eds.), Comprehensive Composite Materials 6. Elsevier Science., pp. 303-325.

Loow, Y.-L., Wu, T.Y., Yang, G.H., Jahim J.Md. Teoh, W.H., Mohammad, A.W., 2016. Role of energy irradiation in aiding pretreatment of lignocellulosic biomass for improving reducing sugar recovery. Cellulose 23, 2761-2789.

Müssig, J., Fischer, H., Graupner, N., Drieling, A., 2010. Testing methods for measuring physical and mechanical fibre properties (plant and animal fibres). In: Müssig, J. (Ed.), Industrial Applications of Natural Fibres: Structure, Properties and Technical Applications. John Wiley \& Sons Ltd., pp. 269-309.

Makuuchi, K., Cheng, S., 2012. Radiation Processing of Polymer Materials and Its Industrial Applications. Wiley, New York.

Marques, G., del Rio, J., Gutierrez, A., 2010. Lipophilic extractives from several non woody lignocellulosic crops (flax, hemp, sisal: abaca) and their fate during alkaline pulping and TCF/ECF bleaching. Bioresour. Technol. 101, 260-267.

Mina, M., Shohrawardy, M., Khan, M., Alam, A., Beg, M., 2013. Improved mechanical performances of triple super phosphate treated jute-fabric reinforced polypropylene composites irradiated by gamma rays. J. Appl. Polym. Sci. 130, 470-478.

Mishra, S., Mohanty, A., Drzal, L., Misra, M., Hinrichsen, G., 2004. A review on pineapple leaf fibers: sisal fibers and their biocomposites. Macromol. Mater. Eng. 289, 955-974.

Misra, M.K., Ragland, K.W., Baker, A.J., 1993. Wood ash composition as a function of furnace temperature. Biomass Bioenergy 4, 103-116.

Mohamed, N.H., Tamada, M., Ueki, Y., Seko, N., 2013. Effect of partial delignification of kenaf bast fibers for radiation graft copolymerization. J. Appl. Polym. Sci. 127, 2891-2895.

Montane, D., Farriol, X., Salvado, J., Jollez, P., Chornet, E., 1998. Fractionation of wheat straw by steam-explosion pre-treatment and alkali delignification. J. Wood Chem. Technol. 18, 171-191.

Morvan, C., Andème-Onzighi, C., Girault, R., Himmelsbach, D.S., Driouich, A., Akin, D.E. 2003. Building flax fibres: more than one brick in the walls. Plant Physiol. Biochem. 
41, 935-944.

Muto, N., Takahashi, K., Yamazaki, H., 1995. Effect of electron beam irradiation on characteristics of paper. Jpn. Tappi J. 49, 1086-1097.

NabiSaheb, D., Jog, J., 1999. Natural fiber polymer composites: a review. Adv. Polym. Technol. 18, 351-363.

O'Sullivan, A.C., 1997. Cellulose: the structure slowly unravels. Cellulose 4, 173-207.

Palm, A., Smith, J., Driscoll, M., Smith, L., Larsen, L.S., 2015. Influence of ionizing radiation on the mechanical properties of a wood-plastic composite. Phys. Procedia 66, 595-603.

Palm, A., Smith, J., Driscoll, M., Smith, L., Larsen, L.S., 2016. Chemical constituent influence on ionizing radiation treatment of a wood?plastic composite. Radiat. Phys. Chem. 124, 164-168.

Paramasivan, T., Abdul Kalam, A.P.J., 1974. On the study of indigenous natural-fibre composites. Fibre Sci. Technol. 7, 85-88.

Pettersen, R.C., 1984. The chemical composition of wood. In: Rowell, R.M. (Ed.), The Chemistry of Solid Wood. American Chemical Society, Washington DC, pp. 76-81.

Phiriyawirut, M., Saenpong, P., Chalermboon, S., Sooksakoolrut, R., Pochanajit, N., Vuttikit, L., Thongchai, A., Supaphol, P., 2008. Isotactic poly(propylene)/wood sawdust composite: effects of natural weathering, water immersion: and gamma-ray irradiation on mechanical properties. Macromol. Symp. 264, 59-66.

Ponomarev, A.V., Ershov, B.G., 2014. Radiation-induced high-temperature conversion of cellulose. Molecules 19, 16877-16908.

Pruzinec, J., Kadlecik, J., Varga, S., Pivovarnicek, F., 1981. Study on the effect of high energy radiation on cellulose. Radiochem. Radioanalyt. Lett. 49, 395-404.

Rivaton, A., Lalande, D., Gardette, J., 2004. Influence of the structure on the $\gamma$-irradiation of polypropylene and on the post-irradiation effects. Nucl. Instrum. Methods Phys. Res. Sect. B 222, 187-200.

Rouif, S., 2004. Radiation cross-linked plastics: a versatile material solution for packaging, automotive. Electrotech. Electron. Radiat. Phys. Chem. 71, 527-530.

Roy, D., Semsarilar, M., Guthrie, J.T., Perrier, S., 2009. Cellulose modification by polymer grafting: a review. Chem. Soc. Rev. 38 (7), 2046-2064.

Sørensen, A., Teller, P.J., Hilstrom, T., Ahring, B.K., 2008. Hydrolysis of Miscanthus for bioethanol production using dilute acid presoaking combined with wet explosion pretreatment and enzymatic treatment. Bioresour. Technol. 99, 6602-6607.

Sgriccia, N., Hawley, M., Misra, M., 2008. Characterization of natural fiber surfaces and naturel fiber composites. Compos.: Part A 39, 1632-1637.

Sharif, J., Mohamad, S., Othman, N., Bakaruddin, N., Osman, H., Güven, O., 2013. Graft copolymerization of glycidyl methacrylate onto delignified kenaf fibers through preirradiation technique. Radiat. Phys. Chem. 91, 125-131.

Shin, H.K., Jeun, J.P., Kim, H.B., Kang, P.H., 2012. Isolation of cellulose fibers from kenaf using electron beam. Radiat. Phys. Chem. 81, 936-940.

Shubhra, Q., Alam, A., 2011. Effect of gamma radiation on the mechanical properties of natural silk fiber and synthetic E-glass fiber reinforced polypropylene composites: a comparative study. Radiat. Phys. Chem. 80, 1228-1232.

Shubhra, Q., Alam, A., Khan, M., Saha, M., Saha, D., Gafur, M., 2010. Study on the mechanical properties, environmental effect: degradation characteristics and ionizing radiation effect on silk reinforced polypropylene/natural rubber composites. Compos.: Part A 41, 1587-1596.

Sjöström, E., 1981. Wood Polysaccharides, Wood Chemistry, Fundamentals and Applications. Academic Press, New York, pp. 51.

Sjöstrom, E., 1993. Wood Chemistry - Fundamentals and Applications, 2nd edition. Academic press, San Diego, pp. 292.

Smith, D.M., Mixer, R.Y., 1959. The effects of lignin on the degradation of wood by gamma irradiation. Radiat. Res. 11, 776-780.

Solpan, D., Torun, M., Güven, O., 2010. Comparison of pre-irradiation and mutual grafting of 2-chloroacrylonitrile on cellulose by gamma-irradiation. Radiat. Phys. Chem. 79, 250-254.
Sonnier, R., Massardier, V., Clerc, L., Lopez-Cuesta, J.-M., Bergeret, A., 2010. Reactive compatibilization of polymer blends by gamma-irradiation: influence of the order of processing steps. J. Appl. Polym. Sci. 115, 1710-1717.

Sonnier, R., Taguet, A., Rouif, S., 2012. Modification of polymer blends by e-beam and gamma-irradiation. In: Mittal, V. (Ed.), Functional Polymer Blends: Synthesis, Properties, and Performance. Boca Raton, CRC Press, pp. 261-304.

Sonnier, R., Otazaghine, B., Viretto, A., Apolinario, G., Ienny, P., 2015. Improving the flame retardancy of flax fabrics by radiation grafting of phosphorus compounds. Eur. Polym. J. 68, 313-325.

Sreekala, M., Thomas, S., 2003. Effect of fibre surface modification on water-sorption characteristics of oil palm fibres. Compos. Sci. Technol. 63, 861-869.

Sreekala, M., Kumaran, M., Thomas, S., 2002. Water sorption in oil palm fiber reinforced phenol formaldehyde composites. Compos.: Part A 33, 763-777.

Stupińska, H., Iller, E., Zimek, Z., Wawro, D., Ciechańska, D., Kopania, E., Palenik, J., Milczarek, S., Stęplewski, W., Krzyżanowska, G., 2007. An environment-friendly method to prepare microcrystalline cellulose. Fibres Text. East. Eur. 15, 167-172.

Tóth, T., Borsa, J., Takács, E., 2003. Effect of preswelling on radiation degradation of cotton cellulose. Radiat. Phys. Chem. 67, 513-515.

Takács, E., Wojnárovits, L., Borsa, J., Földváry, Cs., Hargittai, P., Zöld, O., 1999. Effect of $\gamma$-irradiation on cotton-cellulose. Radiat. Phys. Chem. 55, 663-666.

Takács, E., Wojnárovits, L., Földváry Cs Hargittai, P., Borsa, J., Sajó, I., 2000. Effect of combined gamma-irradiation and alkali treatment on cotton-cellulose. Radiat. Phys. Chem. 57, 399-403.

Takács, E., Wojnarovits, L., Borsa, J., Papp, J., Hargittai, P., Korecz, L., 2005. Modification of cotton-cellulose by preirradiation grafting. Nucl. Instrum. Methods Phys. Res. B 236, 259-265.

Takács, E., Mirzadeh, H., Wojnarovits, L., Borsa, J., Mirzataheri, M., Benke, N., 2007. Comparison of simultaneous and pre-irradiation grafting of $\mathrm{N}$-vinylpyrrolidone to cotton-cellulose. Nucl. Instrum. Methods Phys. Res. B 265, 217-220.

Thakur, R., Sarkar, C.R., Sarmah, R., 1999. Chemical composition of some varieties of ramie and their fibre characteristics. Indian J. Fiber Text. Res. 24, 276-278.

Varghese, S., Kuriakose, B., Thomas, S., 1994. Short sisal fibre reinforced natural rubber composites: high energy radiation: thermal and ozone degradation. Polym. Degrad. Stab. 44, 55-61.

Wahab, R., Mustafa, M.T., Sudin, M., Mohamed, A., Rahman, S., Samsi, H.W., Khalid, I, 2013. Extractives, holocellulose, $\alpha$-Cellulose, lignin and ash contents in cultivated tropical bamboo Gigantochloa brang, G., levis, G. scortechinii and G. wrayi. J. Biol. Sci. 5, 266-272.

Warwicker, J.O., Jeffries, R., Colbran, R.L., Robinson, R.N., 1996. A Review of the Literature on the Effect of Caustic Soda and Other Swelling Agents on the Fine Structure of Cotton. Shirley Institute Pamphlet 93, St Ann's Press, England.

Xu, H., Liu, C.H., Chen, C., Hsiao, B., Zhong, G.J., Li, Z.M., 2012. Easy alignment and effective nucleation activity of ramie fibers in injection-molded poly(lactic acid) biocomposites. Biopolymers 97, 825-839.

Yan, L., Chouw, N., Jayaraman, K., 2014. Flax fibre and its composites - areview. Compos.: Part B 56, 296-317.

Zaman, H., Khan, M., Khan, R., 2012. Comparative experimental measurements of jute fiber/polypropylene and coir fiber/polypropylene composites as ionizing radiation. Polym. Compos. 33, 1077-1084.

Zhang, Y., Huang, Y., Liu, L., Wu, L., 2007. Surface modification of aramid fibers with $\gamma$ ray radiation for improving interfacial bonding strength with epoxy resin. J. Appl. Polym. Sci. 106, 2251-2262.

Zhang, J., 2016. Future prospects for E-beam and X-ray technologies in China and the world. In: Proceedings IMRP 2016. Vancouver, Canada. . http://iiaglobal.com/wpcontent/uploads/2017/05/Book-IMRP-18-PPTs-Part-2-Electron-beam-and-X-RapTechnologies.pdf (Accessed 11 July 2017). 